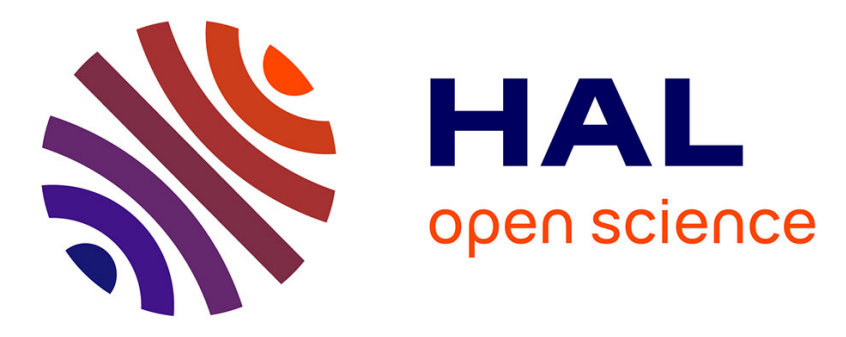

\title{
Scale Transition in Finite Element Simulations of Hydrogen-Plasticity Interactions
}

Y. Charles, Tuan Hung Nguyen, Kevin Ardon, Monique Gaspérini

\section{To cite this version:}

Y. Charles, Tuan Hung Nguyen, Kevin Ardon, Monique Gaspérini. Scale Transition in Finite Element Simulations of Hydrogen-Plasticity Interactions. I.R. Ionescu, S. Queyreau, C.R. Picu, O.U. Salman. Mechanics and Physics of Solids at Micro- and Nano-Scales, 1, ISTE; Wiley, pp.81, 2019, 9781786305312. 10.1002/9781119687566.ch4 . hal-02399165v2

\section{HAL Id: hal-02399165 \\ https://sorbonne-paris-nord.hal.science/hal-02399165v2}

Submitted on 28 Dec 2019

HAL is a multi-disciplinary open access archive for the deposit and dissemination of scientific research documents, whether they are published or not. The documents may come from teaching and research institutions in France or abroad, or from public or private research centers.
L'archive ouverte pluridisciplinaire $\mathbf{H A L}$, est destinée au dépôt et à la diffusion de documents scientifiques de niveau recherche, publiés ou non, émanant des établissements d'enseignement et de recherche français ou étrangers, des laboratoires publics ou privés. 


\section{Scale Transition in Finite Element Simulations of Hydrogen-Plasticity Interactions}

Yann CHARLES

Université Paris 13, Sorbonne Paris Cité, Laboratoire des Sciences des Procédés et des Matériaux, LSPM, CNRS, UPR 3407, 99 avenue Jean-Baptiste Clément, F-93430 Villetaneuse, France

Hung Tuan NGUYEN

Université Paris 13, Sorbonne Paris Cité, Laboratoire des Sciences des Procédés et des Matériaux, LSPM, CNRS, UPR 3407, 99 avenue Jean-Baptiste Clément, F-93430 Villetaneuse, France

Kevin ARDON

Université Paris 13, Sorbonne Paris Cité, Laboratoire des Sciences des Procédés et des Matériaux, LSPM, CNRS, UPR 3407, 99 avenue Jean-Baptiste Clément, F-93430 Villetaneuse, France

Monique GASPERINI

Université Paris 13, Sorbonne Paris Cité, Laboratoire des Sciences des Procédés et des Matériaux, LSPM, CNRS, UPR 3407, 99 avenue Jean-Baptiste Clément, F-93430 Villetaneuse, France 


\subsection{Introduction}

The development of hydrogen-based energetic supply chain leads to increased interest in hydrogen-material interactions phenomenon, especially for metallic materials (see (Djukic et al., 2016; Traidia et al., 2018) for a review of hydrogenassisted cracking models, (Ghosh et al., 2018) for a global description of these interactions for pipeline and pressure vessel, (Djukic et al., 2019) for a comprehensive review of the embrittlement mechanisms interactions in steels and iron, (Martin et al., 2019) for a review on hydrogen-enhanced localized plasticity experimental results, and the recent warning by (Lynch, 2019) on these mechanisms). Aside from the experimental aspect, driven by the progress of observation and characterization devices (such as nano-scales experiments (Alvaro et al., 2015; Barnoush et al., 2010; Deng and Barnoush, 2018; Müller et al., 2019), 3D hydrogen localization by atom probe (Cheng et al., 2013; Koyama et al., 2017) or neutron tomography (Griesche et al., 2014; Pfretzschner et al., 2019), or 2D mapping by Kelvin Probe Force Microscopy (Evers et al., 2013; Melitz et al., 2011)), modeling tools have made notable progress. This progress was helped on the one hand by the increase of computational capacities, and on the other hand, by the development or the adaptation of specific approaches, at several scales (see (Barrera et al., 2018) for a review). Extensive investigations, on several materials or systems, have been made from very local up to mesoscale using one the following numerical tools (see (Aubert et al., 2019) for a global picture of the multi-scale modeling approach):

- Density Functional Theory -DFT-: (Lu et al., 2002) investigates the effect of H atoms on pure aluminum mechanicals properties, while (Jiang and Carter, 2004a) focused on hydrogen diffusion in Iron; (Metsue et al., 2018) investigates the interactions between vacancies and hydrogen in Nickel. Traction Separation laws have been derived from DFT results (Van der Ven and Ceder, 2003) for various material, as aluminum (Ehlers et al., 2016; 2017), iron (Jiang and Carter, 2004b) or nickel (Alvaro et al., 2015));

- Molecular Dynamic -MD-: for instance, investigations on the hydrogen assisted failure have been focused on pre-cracked Nickel single (Wen et al., 2004) or bicrystals (Song and Curtin, 2011), or aluminum single crystal coated by alumina (Verners et al., 2015). Hydrogen-material interactions have also been studied, as in pure iron nano-pillars (Xu et al., 2017), as well as hydrogen-vacancy interplay in tungsten material (Fu et al., 2018). A complete picture is given in (Tehranchi and Curtin, 2019));

- Kinetic Monte Carlo -KMC-: diffusion-related material parameters might be extracted from computations, as in zircon (Zhang et al., 2017). The influence of 
defects on diffusion might be accounted for too, as well as in (Ramasubramaniam et al., 2008) for dislocation in iron, or (Oda et al., 2015) for vacancies in tungsten.

At the component scale, Finite Element (FE) provides the most popular framework for performing numerical simulation on structure in presence of hydrogen (to reproduce hydrogen-sensitivity characterization test, as in (Olden et al., 2009) for SENT, (Charles et al., 2012) for Disk Pressure Test, (Charles et al., 2017a) for U-Bend, or (Ayadi et al., 2017) for shear and tensile test coupled with blistering). In Abaqus software, the hydrogen diffusion and trapping are usually sequentially solved, as in (Moriconi et al., 2014) for instance, while classical elastoplasticity is considered (but in few recent works, in which gradient plasticity models have also been proposed (Martínez-Pañeda et al., 2016)). Fully coupled resolution scheme, as the one used in (Charles et al., 2019), are not that numerous in Abaqus.

Recently, investigations have been made at an intermediate scale: the single crystal one. This scale is strategically pertinent, because it fills the gap between low scales and high ones, allowing one to get a better picture of hydrogen effects on materials at the component scale, improving their reliability. Two main tools have been used in such an approach: dislocation dynamics (e.g., to get the influence of Hydrogen on dislocation motion in steel or iron in 2D (Taketomi et al., 2013) or 3D (Gu and El-Awady, 2018; Yu et al., 2019) configurations or to investigates the hydrogen dragging by mobile dislocations (Sills and Cai, 2016)), and crystal plasticity finite element method (CPFEM). To be more specific, among the finite elements studies at the polycrystal scale, few use crystal plasticity while most of them only deals with hydrogen transport through heterogeneous mediums.

This chapter is mainly dedicated to the scale transition between hydrogen transport and plasticity-induced trapping modeling from the polycrystal scale (using CPFEM), up to the component one. At the crystal scale, mechanical properties and hardening are anisotropic ones, the medium being heterogeneous, while at the macro-scale, every property is isotropic and the model is homogeneous.

Hydrogen transport and trapping is classically described by the diffusion formulation proposed by (Sofronis and McMeeking, 1989) and later improved by (Krom et al., 1999; Sofronis and McMeeking, 1989) (see below section 4.2.2), applied on a Small Scale Yielding configurations. This approach has been implemented in commercial or home-made finite element software, coupled (or not) with mechanical fields, and used in numerous studies to investigate specific features of hydrogen-material interactions in homogeneous structures, including embrittlement or interactions with thermal fields (not being exhaustive, e.g., to study the plastic strain localization during a tensile test on steel (Miresmaeili et al., 2010), 
to analyze the permeation test on steel samples (Legrand et al., 2012), to model or analyze crack propagation (Takayama et al., 2011) or hydrogen repartition after welding in steel pipes (Yan et al., 2014), after welding in steel pipes, or to analyze the effect of a thermomechanical field in a tungsten plasma-facing component (Benannoune et al., 2019a)).

This transport and trapping equation is also used in all of the fewer studies conducted on polycrystalline configurations; among them, three main objectives might be found

- the determination of polycrystalline aggregate effective diffusion properties;

- an investigation of the hydrogen-assisted grain boundary failure;

- the determination of the plastic activities in specific grains in conjunction with experimental results. These studies account nor for hydrogen diffusion neither for hydrogen-plasticity interactions.

This chapter is dedicated to the average diffusion processes in polycrystals, accounting for both mechanical fields (stress, and plastic strain), and non-Fickian effects. After quickly describing the simulations that can found in the literature, and related to hydrogen-assisted failure or plastic strain repartition in a polycrystal, a survey of the finite element works dedicated to the determination of effective diffusion properties through polycrystals will be presented.

CPFEM computations have been used to study the influence of stress and hydrogen concentration heterogeneities on failure. (Rimoli and Ortiz, 2010) has used a 3D pre-cracked regular polycrystal to model an AISI 4340 steel, using trap-free grain boundary diffusion and hydrogen-sensitive cohesive elements to model a transgranular crack propagation. (Benedetti et al., 2018) performed similar computations on steel, without any cracks, and for a given load, as (Benabou, 2019) for copper alloys. (Yu et al., 2017) focused on the effect of grain boundary disorientation on its hydrogen-assisted failure, considering a bi-crystal made of steel with elastic anisotropy and cohesive zones for the grain boundary. Finally, (Wu and Zikry, 2015) conducted 2D computations considering a bulk hydrogen trapping and transport process, and intergranular embrittlement modeled by an overlapping element method.

Few diffusion-free CPFEM models have been used to correlate experimental data and numerical plastic localization (e.g., in steel (Aubert et al., 2016)) or failure (e.g., in aluminum alloys (Pouillier et al., 2012)). 
While claiming to work at the polycrystal scale, numerous investigations are dedicated to the determination of the effective diffusion process through stress-free heterogeneous structures; as a consequence, only a classical Fick law is used with heterogeneous diffusion coefficients. In these studies, mainly in $2 \mathrm{D}$, the grain morphology might be regular or based on a Voronoi tessellation, and the diffusion properties depending on the studied materials. For Nickel material, grains boundaries act as diffusion short-cut, following the pioneering work of (Swiler et al., 1997) and latter (Zhu et al., 2001); the grain boundary type (Legrand et al., 2013), their density (Jothi et al., 2015a), and their connectivity (Osman Hoch et al., 2015) are the main features for extracting an effective diffusion coefficient. Trapping at grain boundaries have been introduced in pure Nickel (Ilin et al., 2016) (Jothi et al., 2015c) or Nickel alloys (Turk et al., 2018), without considering a coupling with mechanical fields. For two-phase steel polycrystals, diffusion short-cut mechanism has also been introduced, not coupled with mechanical fields (Yazdipour et al., 2012); such work focuses mainly on the phase morphology influence on hydrogen transport, as in (Sezgin et al., 2019). Similar studies have also been performed on 3D aluminum polycrystals (Lacaille et al., 2014).

The impacts of mechanical fields (pressure, and trapping by dislocation) on the average diffusivity are not well studied, and most of the works do not include crystal plasticity. For instance, (Olden et al., 2014) consider $\mathrm{J}_{2}$ plasticity in a two-phased steel, and focused on the influence of grain morphology on diffusion and trapping kinetic, while (Shibamoto et al., 2017) used a pre-computed pressure field and a regular grain shape, for the same aim. Last, (Jothi et al., 2014) only considers elastic anisotropy in Nickel polycrystals.

CPFEM is used in a 3D regular iron polycrystal in (Charles et al., 2017b), and in a 2D Voronoi steel one in (Hassan et al., 2018): in these two works, the influence of a predeformation on hydrogen diffusion is investigated, accounting for both pressure stress and dislocation induced traps. Last, (Ilin et al., 2014) focused on hydrogen redistribution in a $2 \mathrm{D}$ steel polycrystal due to an applied load, and at the crystal scale, FE investigations have also been performed to investigate the experimentally measured diffusion anisotropy in Nickel single crystal (J.-X. Li et al., 2017), considering elastic anisotropy and vacancy-induced strain. Very few works have investigated the reformulation of crystal plasticity laws to account for the hydrogen effect on slips (Bal et al., 2017; Birnbaum and Sofronis, 1994; Cailletaud, 2009; Kumar et al., 2019; Vasios, 2015), or the correspondence between the diffusion process through a polycrystal and the equivalent homogeneous medium (Charles et al., 2018; Jothi et al., 2015b). 
From the previous picture, it appears that CPFEM is not commonly used in computations, and especially for the effective diffusion coefficient evaluation.

The different modeling assumptions used in this chapter are first presented, as well as the tools developed required to perform multi-scale finite element computations (section 4.2). Afterward, two specific points are focused on to illustrate the consequences of scale transition in finite element modeling, while dealing with hydrogen transport and trapping:

- on section 4.3, a reformulation of the dislocation-related trap density function is proposed for iron material, to get the same transport kinetic through a polycrystal and the corresponding homogenous sample.

- section 4.4. is dedicated to the presentation of the model proposed by Dadfarnia (Dadfarnia et al., 2015), aiming at including hydrogen dragging by dislocation in a homogeneous medium. An adaptation of this approach at the crystal scale is proposed. The consequences at the polycrystal scale of such formalism, accounting for textures, have been investigated.

\subsection{Modeling assumptions}

The modeling assumptions at the polycrystal scale are directly adapted from the one used at the macroscopic scale, considering few adaptations linked to the specific way plasticity occurs in crystals.

\subsubsection{Crystal plasticity mechanical behavior}

The anisotropic elasticity is defined through $C_{i j}$ elastic constants.

The crystal plasticity is described by a classical viscous formulation (Asaro, 1983) for numerical purpose only. The slip rate $\dot{\gamma}^{\alpha}$ on the $\alpha^{\text {th }}$ slip system, defined by its normal vector $\boldsymbol{n}^{\alpha}$ and its slip direction $\boldsymbol{m}^{\alpha}$, is related to the resolved shear stress $\tau^{\alpha}$ by a power-law relationship

$$
\dot{\gamma}^{\alpha}=\dot{a}_{0} \frac{\tau^{\alpha}}{\tau_{c}^{\alpha}}\left|\frac{\tau^{\alpha}}{\tau_{c}^{\alpha}}\right|^{n-1}
$$


$\tau_{c}^{\alpha}$ is the critical resolved shear stress, $\dot{a}_{0}$ is a reference strain rate, and $\mathrm{n}$ the strain-rate sensitivity, chosen high enough to avoid viscous effects. From slip rates on each system, the global plastic strain rate tensor is

$$
\dot{\boldsymbol{\varepsilon}}_{p}=\sum_{\alpha}\left(\boldsymbol{m}^{\alpha} \otimes \boldsymbol{n}^{\alpha}\right) \dot{\gamma}^{\alpha}
$$

$\tau^{\alpha}$ is obtained by

$$
\tau^{\alpha}=\frac{1}{2}\left(\boldsymbol{m}^{\alpha} \otimes \boldsymbol{n}^{\alpha}+\boldsymbol{n}^{\alpha} \otimes m^{\alpha}\right): \boldsymbol{\sigma}
$$

where $\sigma$ is the local stress field; $\otimes$ denotes the tensorial product, and ' $:$ ' the tensorial contraction. The hardening law is described by (Peirce et al., 1982)

$$
\dot{\boldsymbol{\tau}}^{\alpha}=\sum_{\alpha} h_{\alpha \beta} \dot{\gamma}^{\beta}
$$

where $h_{\alpha \beta}$ represent the self-hardening and $h_{\alpha \beta, \alpha \neq \beta}=q h_{\alpha \alpha}$ the latent one, with

$$
h_{\alpha \alpha}=h_{0} \operatorname{sech}^{2}\left|\frac{h_{0} \gamma}{\tau_{s}-\tau_{0}}\right|
$$

$\gamma=\sum_{\alpha} \int_{0}^{t}\left|\dot{\gamma}^{\alpha}\right| d t$ is the cumulated shear strain. $\mathrm{h}_{0}, \tau_{s}$ and $\tau_{0}$ are material parameters.

No influence of hydrogen on mechanical behavior is taken into account in the present work.

\subsubsection{Hydrogen transport equation}

The hydrogen transport equation is based on the local balance between hydrogen concentration in normal interstitial lattice sites (NILS) and hydrogen concentration in trapping sites (Krom et al., 1999; Oriani, 1970) 


$$
K_{T} \theta_{L}=\frac{\theta_{T}}{1-\theta_{T}}
$$

where $\mathrm{K}_{\mathrm{T}}$ represents the equilibrium constant with $\mathrm{K}_{\mathrm{T}}=\exp \left(-\mathrm{W}_{\mathrm{B}} / \mathrm{RT}\right)\left(\mathrm{W}_{\mathrm{B}}\right.$ being the trap binding energy). NILS hydrogen concentration $C_{L}$ relates to NILS density $N_{L}$ by $\mathrm{C}_{\mathrm{L}}=\mathrm{N}_{\mathrm{L}} \theta_{\mathrm{L}}$ whereas trapped hydrogen density $\mathrm{C}_{\mathrm{T}}$ relates to trap density $\mathrm{N}_{\mathrm{T}}$ by $\mathrm{C}_{\mathrm{T}}=\mathrm{N}_{\mathrm{T}} \theta_{\mathrm{T}} ; \theta_{\mathrm{L}}$ and $\theta_{\mathrm{T}}$ are respectively NILS and trapping sites occupancy, assuming that $\theta_{\mathrm{L}}<<1$. The hydrogen diffusion equation, as proposed by Sofronis et al. (Sofronis and McMeeking, 1989) is thus

$$
\frac{\partial\left(C_{T}+C_{L}\right)}{\partial t}+\nabla \varphi_{L}=0
$$

$\varphi_{\mathrm{L}}$ is the Fickian flux, modified to account for the effect of hydrostatic pressure (Bogkris et al., 1971; Dederichs and Schroeder, 1978; J. C. M. Li et al., 1966; Sofronis and McMeeking, 1989):

$$
\varphi_{L}=-D_{L} \nabla C_{L}-\frac{V_{H}}{R T} C_{L} \nabla P_{H}
$$

where $D_{L}$ is the hydrogen diffusion coefficient, $R$ the perfect gas constant, $T$ the absolute temperature, $\mathrm{V}_{\mathrm{H}}$ the partial molar volume of hydrogen in solid solution and $\mathrm{P}_{\mathrm{H}}$ the hydrostatic pressure, equal to $-1 / 3$ tr $\sigma$.

The global transport and trapping equation might be derived from Equations [4.7] and [4.8], as

$$
\frac{C_{T}\left(1-\theta_{T}\right)+C_{L}}{C_{L}} \frac{\partial C_{L}}{\partial t}+\nabla\left(-D_{L} \nabla C_{L}-\frac{V_{H}}{R T} C_{L} \nabla P_{H}\right)+\theta_{T} \frac{d N_{T}}{d \varepsilon_{p}} \dot{\varepsilon}_{p}=0
$$

$\mathrm{N}_{\mathrm{T}}$ is here assumed to be only function of the equivalent plastic strain $\varepsilon_{\mathrm{p}}$ (Kumnick and Johnson, 1980), corresponding to a phenomenological description of the trapping by dislocations (see Equation [4.12] bellow). It is worth noting that Equation [4.6] might be replaced by the following kinetic reaction (McNabb and Foster, 1963)

$$
\frac{\partial \theta_{T}}{\partial t}=k \theta_{L}\left(1-\theta_{T}\right)-p \theta_{T}
$$


where $\mathrm{k}$ and $\mathrm{p}$ represents the probability of respectively trapping and detrapping processes, so that $\mathrm{K}_{\mathrm{T}}=\mathrm{k} / \mathrm{p}$. In this work, however, Oriani's assumption has been considered (equation [4.6]).

\subsubsection{Implementation}

The previous constitutive laws have been implemented in Abaqus FE software, based on previous works (Charles et al., 2017b; 2017a); the main features are recalled below. Several user subroutines (Simulia, 2011) have been developed:

- an UMAT one, based on the Huang one (Huang, 1991; Kysar, 1991), allowing to include anisotropic crystal plasticity in Abaqus (Equations [4.1] to [4.5]);

- an UMATHT one, to define the coupled transport (Equation [4.9]);

- an ORIENT subroutine to impose a local crystal orientation.

The flowchart of the user subroutine integration in Abaqus is presented on Figure 4.1; the developments have been made in order to simultaneously solve the mechanical and diffusion problem. The procedure used is 'coupled temp-disp', based on the analogy between the thermal and Fick diffusion equations (Oh et al., 2010).

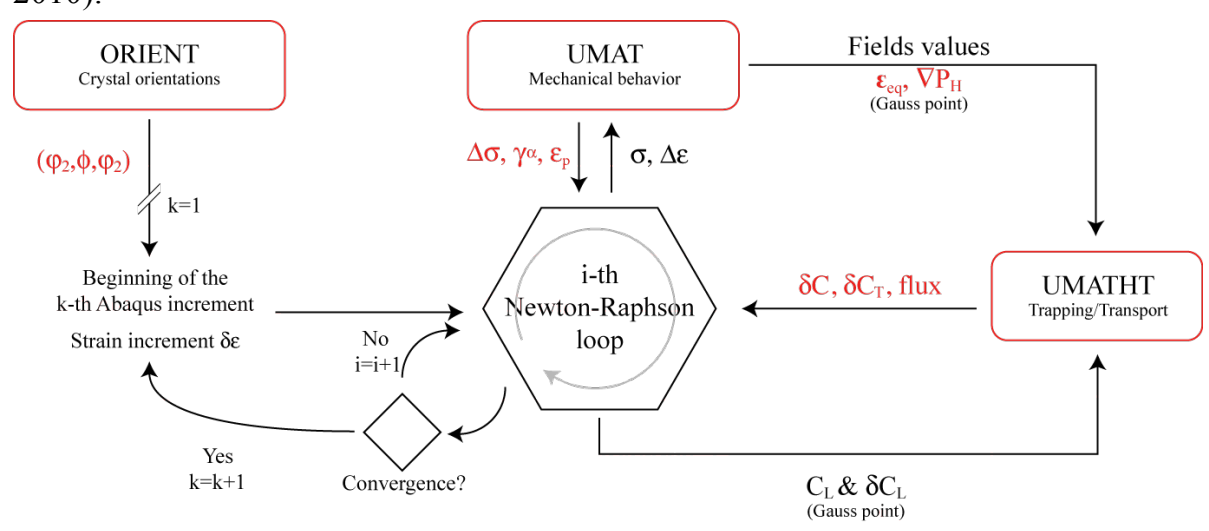

Figure 4.1. Coupled transport-trapping problem implementation in Abaqus. In red is underlined the data computed in the subroutines and transferred to other subroutines or Abaqus program.

Kinetic trapping (Equation [4.10]) (Benannoune et al., 2018; Charles et al., 2018), as well as transient thermal fields (Benannoune et al., 2019b; Vasikaran et al., 2019) might also been included in computations. 


\subsubsection{Mechanical parameters}

For all of the applications proposed in the present article, $\alpha$-iron was considered. The anisotropic elasticity is described by the $C_{11}, C_{21}$, and $C_{44}$ constants for cubic symmetry (see Table 4.1).

\begin{tabular}{|c|c|c|}
\hline $\mathrm{C}_{11}(\mathrm{MPa})$ & $\mathrm{C}_{12}(\mathrm{MPa})$ & $\mathrm{C}_{44}(\mathrm{MPa})$ \\
\hline 236900 & 140600 & 116000 \\
\hline
\end{tabular}

Table 4.1. Elastic parameters for the crystal elastoplastic mechanical behavior (Lord and Beshers, 1965).

The values of $\mathrm{h}_{0}, \tau_{0}$ and $\tau_{s}$ were chosen to be representative of tensile test performed on pure iron single crystals (Franciosi et al., 2015; Le, 2013) (see Table 4.2). Only the 12 slip systems $\{110\}\langle 111\rangle$ for bec structures were used for the sake of simplicity.

\begin{tabular}{|c|c|c|c|}
\hline $\mathrm{q}$ & $\mathrm{h}_{0}(\mathrm{MPa})$ & $\tau_{0}(\mathrm{MPa})$ & $\tau_{s}(\mathrm{MPa})$ \\
\hline 1.1 & 175 & 30 & 100 \\
\hline
\end{tabular}

Table 4.2. Hardening parameters for the crystal elastoplastic mechanical behavior.

$\dot{a}_{0}$ and $\mathrm{n}$ values were chosen equal to respectively $0.001 \mathrm{~s}^{-1}$ and 110 . Last, diffusion parameters at $300 \mathrm{~K}$ for $\alpha$-iron are reported on Table 4.3 (Hirth, 1980; Krom et al., 1999; Sofronis and McMeeking, 1989), assuming their coincidence at both component and crystal scale.

\begin{tabular}{|c|c|c|c|}
\hline $\mathrm{D}_{\mathrm{L}}\left(\mathrm{m}^{2} / \mathrm{s}\right)$ & $\mathrm{V}_{\mathrm{H}}\left(\mathrm{m}^{3} / \mathrm{mol}\right)$ & $\mathrm{N}_{\mathrm{L}}\left(\mathrm{atom} / \mathrm{m}^{3}\right)$ & $\mathrm{W}_{\mathrm{B}}(\mathrm{kJ} / \mathrm{mol})$ \\
\hline $1.27 \times 10^{-8}$ & $2 \times 10^{-6}$ & $8.46 \times 10^{28}$ & -60 \\
\hline
\end{tabular}

Table 4.3. Hydrogen-related parameters for $\alpha$-iron.

The mechanical behavior of the polycrystal Representative Elementary Volume (REV) is defined based on a Voce law, the yield stress $\sigma_{\mathrm{Y}}$ being related to the equivalent plastic strain $\varepsilon_{\mathrm{p}}$ by 


$$
\sigma_{Y}=\sigma_{0}+R_{s a t}\left(1-e^{-C \varepsilon_{p}}\right)
$$

$\sigma_{0}, R_{\text {sat }}$ and $\mathrm{C}$ are material parameters, identified from the mean polycrystalline tensile curves (Charles et al., 2017b). The obtained parameters are reported on Table 4.4, assuming an overall isotropic elasticity is described with the Young modulus E and the Poisson ratio $v$

\begin{tabular}{|c|c|c|c|c|}
\hline $\mathrm{E}(\mathrm{GPa})$ & $v$ & $\sigma_{0}(\mathrm{MPa})$ & $\mathrm{R}_{\text {sat }}(\mathrm{MPa})$ & $\mathrm{C}$ \\
\hline 215 & 0.3 & 70.3 & 220.4 & 7.4 \\
\hline
\end{tabular}

Table 4.4 Mechanical parameters corresponding to the average polycrystal behavior.

At both scale, as a first approximation, the same trap density was used corresponding to the one identified for $\alpha$-iron (Johnson, 1988; Kumnick and Johnson, 1980; Sofronis and McMeeking, 1989)

$$
\log N_{T}=23.26-2.33 e^{-5.5 \varepsilon_{p}}
$$

\subsection{Identification of a trap density function at the crystal scale}

In a previous work (Charles et al., 2017b), we have shown that, if no trapping by dislocations is considered, the mechanical heterogeneities induced by the polycrystalline features do not influence the overall hydrogen diffusion in samples, whatever the grain numbers. If trapping is included, however, important differences were observed: if the diffusion parameters identified at the macro scale might be used at the crystal one, the trap density must be adapted and the formulation presented on equation [4.12] is no longer relevant.

We aim in the following to propose a reformulation of $\mathrm{N}_{\mathrm{T}}$ at the crystal scale so that the transport and plasticity-induced trapping process at both scales becomes equivalent: for a given polycrystal and its homogeneous equivalent model, several average plastic strains were considered, and the average diffusion processes were compared. Last, $\mathrm{N}_{\mathrm{T}}$ was identified at the crystal scale, based on the time-lag method (Fallahmohammadi et al., 2013; Kumnick and Johnson, 1980). 


\subsubsection{Geometry, mesh, and boundary conditions applied on the polycrystals}

The considered polycrystalline aggregate is set as a parallelepipedic bar, with a square base surface equal to $0.001^{2 / 3} \mathrm{~mm}^{2}$ and a height $\mathrm{h}=0.43 \mathrm{~mm}$, made of truncated octahedrons (see Figure 4.2). Each grain is meshed with 60 full integration 8 nodes tri-linear elements.

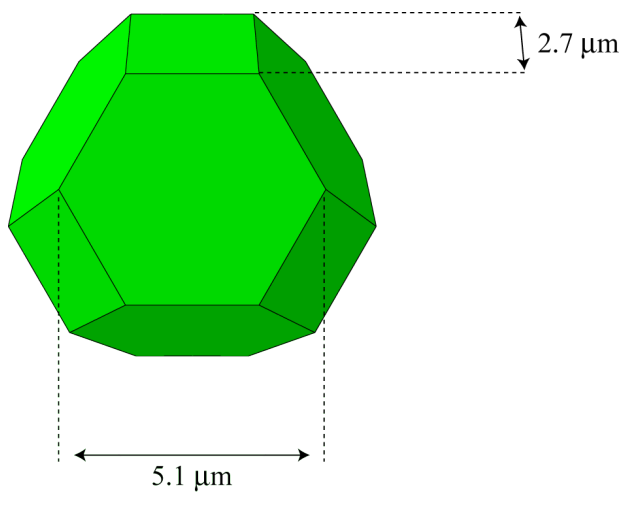

Figure 4.2. A truncated octahedron (Charles et al., 2017b).

The polycrystal geometry has been generated by the Neper program (Quey et al., 2011) and imported in Abaqus CAE using python scripts (Simulia, 2011).

Grains orientation have been defined by an ORIENT User Subroutine (Simulia, $2011)$, using random sets of Euler angles $\left(\varphi_{1}, \Phi, \varphi_{2}\right)$, considering an overall isotropic texture.

Computations are made of two-steps: first a purely mechanical simulation, secondly a diffusion one under a constant mechanical loading.

\subsubsection{Mechanical loading}

In the first step, a displacement is imposed on the upper surface, for to a given uniaxial strain $(0,10,20,30,4050$ and $60 \%)$. Symmetric boundary conditions have been set on the lower one (Figure 4.3a), and uniform mixed-orthogonal (or block) on the lateral ones, to model periodicity (Charles et al., 2010; Salahouelhadj and Haddadi, 2010). 


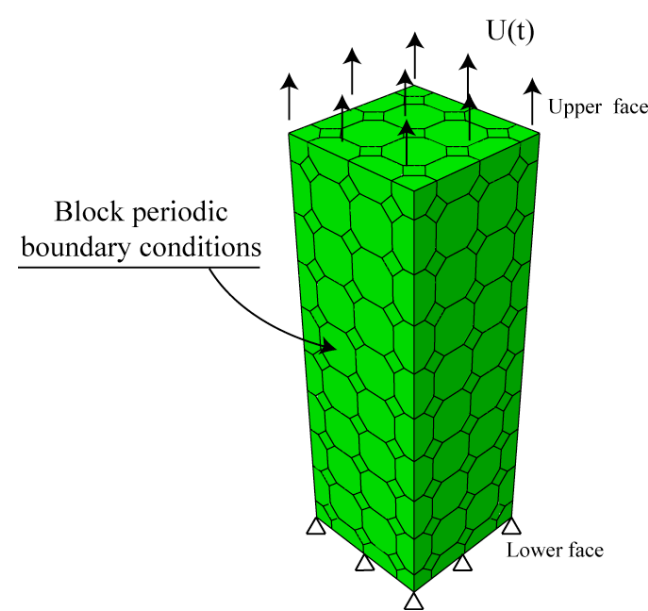

(a)

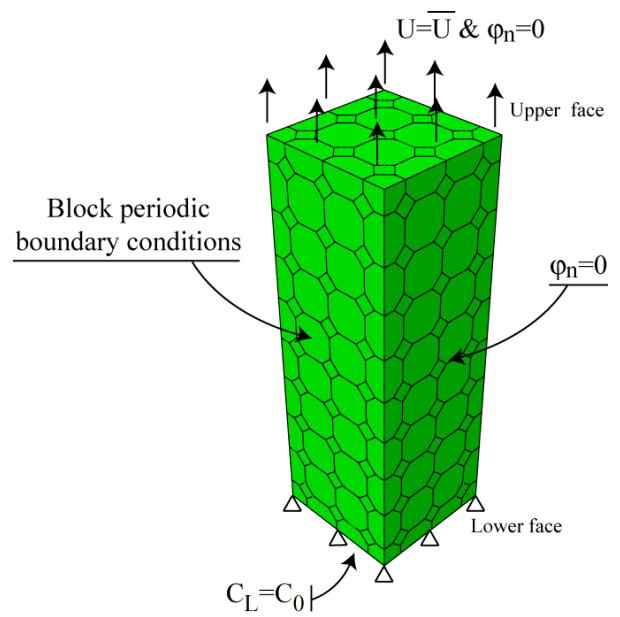

(b)

Figure 4.3. Boundary conditions for (a) the mechanical computation up to a given macroscopic strain and (b) the diffusion computations considering a constant applied strain. For $h=0.43 \mathrm{~mm}$, the bar is made of 167 grains (Charles et al., 2017b).

\subsubsection{Diffusion and trapping}

In the second step, hydrogen transport occurs under constant strain. A zero normal flux is imposed on each polycrystal faces but on the lower one, where $\mathrm{C}_{\mathrm{L}}=\mathrm{C}_{0}=2.084 \times 10^{21}$ atom $/ \mathrm{m}^{3}$ (Sofronis and McMeeking, 1989) is instantaneously imposed at the beginning of the diffusion step (Figure 4.3b). This value is computed from the Sivert law established in (Johnson, 1974), and corresponds to the quantity of the steady state hydrogen concentration in a sample surrounded by an dihydrogen gas, the pressure of which being 1 bar.

Hydrogen transport and trapping then occur, based on equation [4.9]; the computation is stopped as soon as the steady state is reached. 


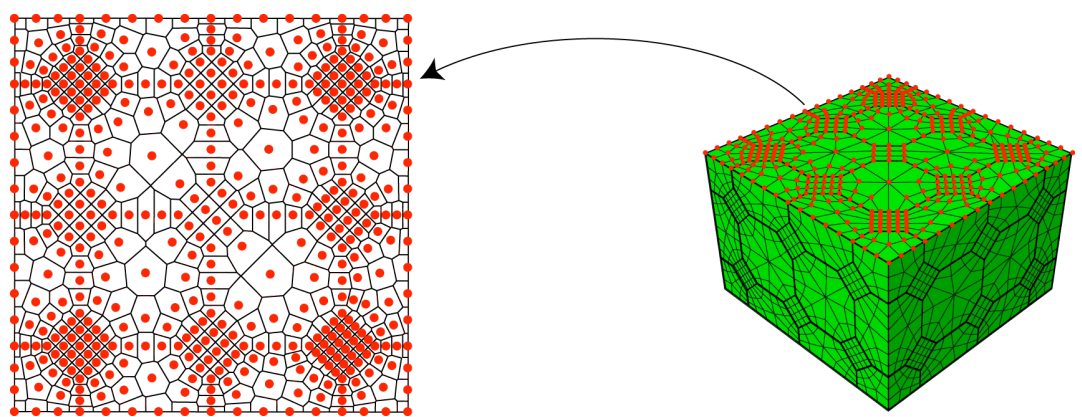

Figure 4.4. Voronoi tessellation of the polycrystal upper face designed to get the upper face mean $C_{L}$ value evolution with time; each red seed corresponds to a node (here, 465 nodes) (Charles et al., 2017b).

For all computations, the diffusive hydrogen concentration values $\mathrm{C}_{\mathrm{L}}$ have been saved for all of the upper face nodes, and at each computed time, from which its statistical features have been derived. To compute the average $\left\langle\mathrm{C}_{\mathrm{L}}\right\rangle$, the value of each node have been weighted by the surface of the corresponding cell in the Voronoi tessellation of the upper bar face (see Figure 4.4).

\subsubsection{Results}

The $\left\langle\mathrm{C}_{\mathrm{L}} / \mathrm{C}_{0}\right\rangle$ evolution with time on the upper bar face has been computed for all of the considered applied strains, and for the two models (homogeneous and polycrystalline). To discuss the influence of trapping on hydrogen transport, the time lag method has been used (Barrer, 1951), the trap-free time lag $t_{L}$ and with trapping $\mathrm{t}_{\mathrm{T}}$ being extracted from computations results. These two times lag are supposed to be linked by the following linear relationship (Fallahmohammadi et al., 2013; Kumnick and Johnson, 1980)

$$
\frac{t_{T}}{t_{L}}-1=\alpha \frac{N_{T}}{C_{0}}
$$

where $\alpha$ is a constant, wich depends on the considered test.

\subsubsection{Identification of $N_{T}\left(\varepsilon_{p}\right)$ at the crystal scale}

Plotting $t_{L} / t_{T}$ versus $N_{T}$ for the homogeneous bar (Figure 4.5) shows a linear relationship, as expected, with a slope $\alpha=5.69 ; \mathrm{N}_{\mathrm{T}}$ values have been computed using equation [4.12], knowing, for each computation, the value of the equivalent plastic stain $\varepsilon_{\mathrm{p}}$. $\alpha$ differs from the value obtained in the previous study (Charles et al., 
2017b) for the same configuration $(\alpha=4)$, because in this latter, $t_{L}$ values has been computed using an explicit relationship (Barrer, 1951) and not extracted from computations.

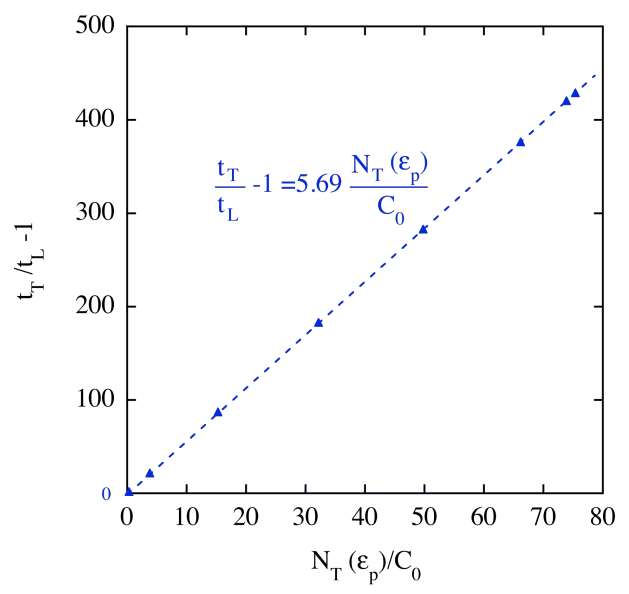

Figure 4.5. Evolution of $t_{T} / t_{L}$ with $N_{T}$ for several applied strains.

This $\alpha$ value might then be used to extract, from polycrystalline $\left\langle\mathrm{C}_{\mathrm{L}} / \mathrm{C}_{0}\right\rangle$ curves, the trap density as a function of the average equivalent plastic strain in the polycrystal $\left\langle\varepsilon_{\mathrm{p}}\right\rangle$ (Figure 4.6b). $\left\langle\varepsilon_{\mathrm{p}}\right\rangle$ is computed as following

$$
\left\langle\varepsilon_{p}\right\rangle=\sum_{\substack{\text { Gauss } \\ \text { Point }}} V_{i} \varepsilon_{p}^{i}
$$

where $\mathrm{V}_{\mathrm{i}}$ and $\varepsilon_{p}^{i}$ are respectively the volume and equivalent plastic strain associated to the integration point $\mathrm{n}^{\circ} \mathrm{i}$.

As already observed (Charles et al., 2017b), the transport and trapping process in the polycrystalline structure is slower than in the equivalent homogeneous medium, inducing a higher identified trap density value. 


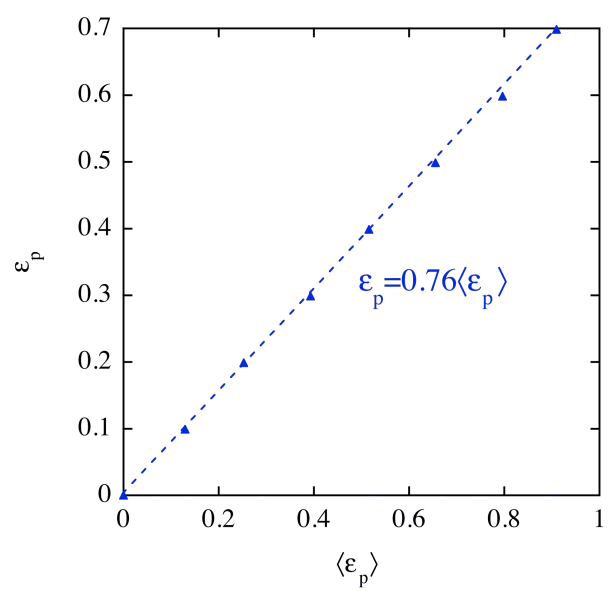

(a)

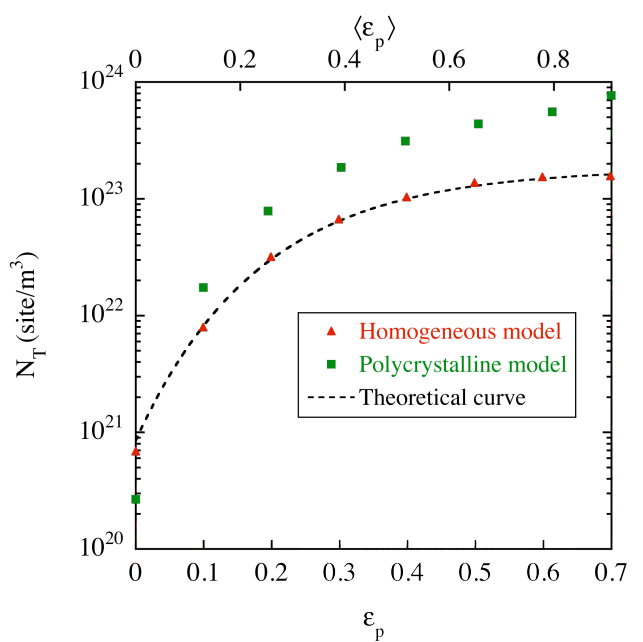

(b)

Figure 4.6. (a) Relationship between $\left\langle\varepsilon_{p}\right\rangle$ and $\varepsilon_{p}$, respectively the average equivalent plastic strain in the polycrystalline model and the equivalent plastic strain in the homogenous one. (b) variation of $N_{T}$ with both $\left\langle\varepsilon_{p}\right\rangle$ and $\varepsilon_{p}$, computed using the timelag method and $\alpha=5.69$. It is worth noting that this value has been identified so that the $N_{T}$ variation with $\varepsilon_{p}$ extracted from the homogeneous model computations fits with the theoretical curve $N_{T}\left(\varepsilon_{p}\right)$.

Plotting $\varepsilon_{\mathrm{p}}$ versus $\left\langle\varepsilon_{\mathrm{p}}\right\rangle$ leads to a linear relationship (Figure 4.6a): as a consequence, to have a coincidence between the transport and trapping process through a polycrystal and its equivalent homogeneous medium, it is only needed to impose at the crystal scale a trap density function of the equivalent plastic strain shcu that

$$
\log N_{T}=23.26-2.33 e^{-5.5 \times 0.76 \times \varepsilon_{p}}
$$

\subsubsection{Validation}

The comparison of the transport and trapping process in the homogenous and in the polycrystalline samples predeformed at $20 \%$ is shown on Figure 4.7. As it can be seen, the average transport processes in the two samples becomes equivalent while using the modified $\mathrm{N}_{\mathrm{T}}$ formulation for the polycrystal (Equation [4.15]). The steady state value reached by $\left\langle\mathrm{C}_{\mathrm{L}} / \mathrm{C}_{0}\right\rangle$ on the polycrystal upper face is greater than 1 , due to differences in term of mean $\mathrm{P}_{\mathrm{H}}$ value between the lower and the upper faces (Charles et al., 2017b): as soon as the $\nabla \mathrm{P}_{\mathrm{H}}$ contribution in Equation [4.9] is no longer accounted for (green triangles in Figure 4.7), differences between the average transport process through polycrystalline and homogeneous media vanished. 


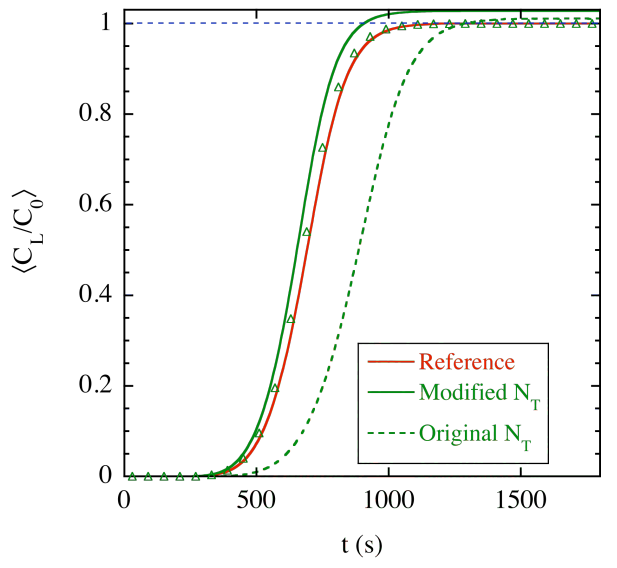

Figure 4.7. Comparison of the $\left\langle C_{L} / C_{0}\right\rangle$ evolution with time on the sample upper face for the polycrystalline (green line) and for the homogeneous samples (red line). For the polycrystalline model, and for the sake of comparison is also plotted the $\left\langle C_{L} / C_{0}\right\rangle$ evolution considering the initial $N_{T}$ formulation (dashed green line).

To challenge the formulation proposed in Equation [4.15], we have simultaneously imposed the displacement and the hydrogen concentration depicted on Figure 4.3, for the two models, considering Equation [4.15] for the trap density at the crystal scale, and Equation [4.12] at the sample one. The $\left\langle\mathrm{C}_{\mathrm{L}} / \mathrm{C}_{0}\right\rangle$ evolutions with time on the models upper face are plotted on Figure 4.8: as it can be seen, the modified $\mathrm{N}_{\mathrm{T}}$ formulation improve significantly the correspondence between the trapping and transport process at both component and polycrystal scales, even if further investigations are needed to improve this correspondence. 


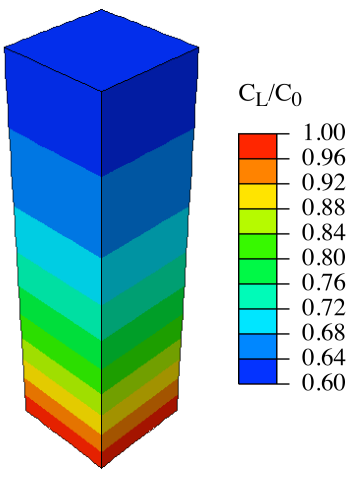

(a)

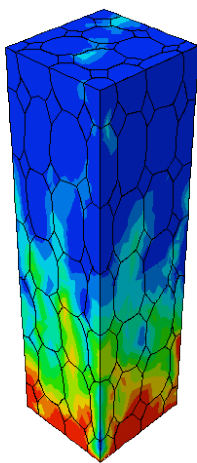

(b)

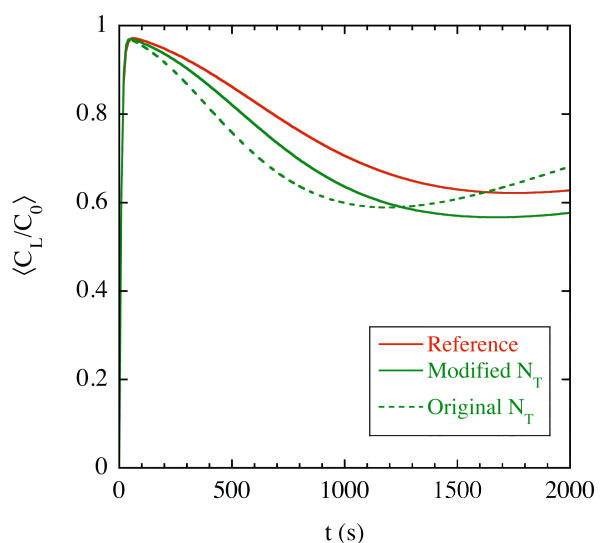

(c)

Figure 4.8. Maps of $C_{L} / C_{0}$ at $:=2000 s$ for (a) the homogeneous and (b) the polycrystalline models. (c) $\left\langle C_{L} / C_{0}\right\rangle$ evolution with time for the two models (homogeneous in red and polycrystalline in green) on the samples upper face.

This adaptation of $\mathrm{N}_{\mathrm{T}}$ is a first step toward a proper description of the trapping process at the crystal scale using diffusion-based equations. While especially dealing with trapping by dislocations, the scale transition computations point out that the equivalent plastic strain might not be the most relevant measure to describe the trap evolution; a much convincing one might be the dislocation density (see e.g. (Oudriss et al., 2012) for Nickel), but such an analysis is beyond the scope of the present numerical study.

This trapped hydrogen, furthermore, can be transported by the dislocation movement. It is indeed showed by experimental works (see, among other, (Albrecht et al., 1982; Berkowitz and Heubaum, 1983; Donovan, 1976; Hirth and Johnson, 1983; Hwang and Bernstein, 1986; 1983)) that hydrogen trapped near dislocations can diffuse during dislocations movement, creating an additional diffusion flux, which contributes to faster hydrogen transport due to the higher dislocation velocity than hydrogen diffusion rate. This hydrogen transport mechanism is then expected to significantly modify the occurrence and kinetics of material-hydrogen interactions and hydrogen embrittlement, and has to be accounted for in the hydrogen transport simulations. 


\subsection{Adaptation of the Dadfarnia's model at the crystal scale}

Recently, Dadfarnia and al. (Dadfarnia et al., 2015) extended the Sofronis and McMeeking model (Krom et al., 1999; Krom and Bakker, 2000; Sofronis and McMeeking, 1989) to include hydrogen transport by dislocation by adding an extra flux term. Applied to the simulation of hydrogen concentration ahead a crack tip in small scale yielding with isotropic elastoplastic material (as in previous works (Sofronis and McMeeking, 1989)), they showed through a parametric study the effect of the hydrogen transport by dislocation both for bcc and fcc materials, which permits to improve the simulation of hydrogen transport.

We do not aim here to review their assumptions and modeling, but just to propose a direct adaptation of this approach at the crystal scale, to illustrate the influence of discrete predetermined transport directions on this formalism on the one hand, and its consequence on the transport process through a polycrystalline media on the other hand.

\subsubsection{Formulation at the polycrystal scale}

Following (Dadfarnia et al., 2015), equation [4.7] must be rewritten as

$$
\frac{\partial\left(C_{L}+C_{T}\right)}{\partial t}+\nabla \cdot\left(\varphi_{L}+\varphi_{d}\right)=0
$$

where $\varphi_{\mathrm{d}}$ is the hydrogen flux associated with mobile dislocation, defined as $\theta_{T} N_{T}^{m} \boldsymbol{v}_{d} \cdot \mathbf{v}_{\mathrm{d}}$ is the dislocation velocity, and $N_{T}^{m}$ the part of $\mathrm{N}_{\mathrm{T}}$ associated with mobile dislocation. This expression might be generalized to various slip systems, so that

$$
\varphi_{d}=\sum_{\alpha} \varphi_{d}^{\alpha}
$$

with

$$
\varphi_{d}^{\alpha}=\theta_{T} N_{T}^{m, \alpha} \boldsymbol{v}_{d}^{\alpha}
$$


$\varphi_{d}^{\alpha}$ is the hydrogen flux carried by the movement of mobile dislocations along the slip direction of the $\alpha^{\text {th }}$ slip system. $v_{d}^{\alpha}$ represents the dislocation velocity in the slip plan $\alpha$, in which the trap density associated with mobile dislocation is $N_{T}^{m, \alpha}$. Following (Dadfarnia et al., 2015), this function can be calculated from mobile dislocation density $\rho_{m}^{\alpha}$ as follow:

$$
N_{T}^{m, \alpha}=\frac{\lambda \rho_{m}^{\alpha}}{a}
$$

where a is lattice parameter and $\lambda=\sqrt{2}$ or $\sqrt{3}$ for bcc or fcc lattice. Orowan's law links the slip rate in slip system $\alpha$

$$
\dot{\gamma}^{\alpha}=b \rho_{m}^{\alpha}\left\|v_{d}^{\alpha}\right\|
$$

$\left\|v_{d}^{\alpha}\right\|$ is the velocity vector's magnitude and $\mathrm{b}$ the Burger's one. Hence, $\left\|v_{d}^{\alpha}\right\|$ is determined by $\boldsymbol{v}_{d}^{\alpha}=\left\|\boldsymbol{v}_{d}^{\alpha}\right\| \boldsymbol{m}^{\alpha}$, where $\boldsymbol{m}^{\alpha}$ represents the slip direction of dislocations movement in the $\alpha^{\text {th }}$ slip system. It is important to underline that we do not account for potential transport towards the $-\boldsymbol{m}^{\alpha}$ direction. From equation [4.19], one obtains

$$
\rho_{m}^{\alpha}=\frac{\dot{\gamma}^{\alpha}}{b\left\|v_{d}^{\alpha}\right\|}
$$

Substituting [4.20] into [4.21] leads to

$$
N_{T}^{m, \alpha}\left\|v_{d}^{\alpha}\right\|=\frac{\lambda \dot{\gamma}^{\alpha}}{b a}
$$

Therefore, the flux of hydrogen transported by mobile dislocations along the $\alpha^{\text {th }}$ slip system is 


$$
\boldsymbol{\varphi}_{d}^{\alpha}=\theta_{T} \frac{\dot{\gamma}^{\alpha}}{b\left\|\boldsymbol{v}_{d}^{\alpha}\right\|} \boldsymbol{m}^{\alpha}
$$

Then, using equation [4.23], the extension to various slip systems of the hydrogen transport by mobile dislocations in the hydrogen transport used by Dadfarnia et al. (Dadfarnia et al., 2015) leads to

$$
\begin{aligned}
\frac{C_{T}\left(1-\theta_{T}\right)+C_{L}}{C_{L}} \frac{\partial C_{L}}{\partial t} & +\nabla\left(-D_{L} \nabla C_{L}-\frac{V_{H}}{R T} C_{L} \nabla P_{H}\right) \\
& +\theta_{T} \frac{d N_{T}}{d \varepsilon_{p}} \dot{\varepsilon}_{p}+\nabla\left(\frac{\lambda \theta_{T}}{b a} \sum_{\alpha} \dot{\gamma}^{\alpha} \boldsymbol{m}^{\alpha}\right)=0
\end{aligned}
$$

$\mathrm{N}_{\mathrm{T}}$ being here assumed to be only a function of the equivalent plastic strain $\varepsilon_{\mathrm{p}}$ (Kumnick and Johnson, 1980) and, assuming equilibrium between trapped and diffusive hydrogen (Oriani, 1970). The lattice parameter $a$ and the burger vector $b$ were set to $0.287 \mathrm{~nm}$ and $0.248 \mathrm{~nm}$ respectively (Dadfarnia et al., 2015).

\subsubsection{Application to single crystals}

A $\alpha$-Fe bcc single crystal is here considered; only the 12 slip systems $\{110\}\langle 111\rangle$ for bcc structures are considered in the present study (the numbering of these slip systems is given in Appendix 4.7). The considered single crystal is a cube of side $1 \mathrm{~mm}$, regularly meshed with 1000 tri-linear full integration hexahedral elements (Figure 4.9).

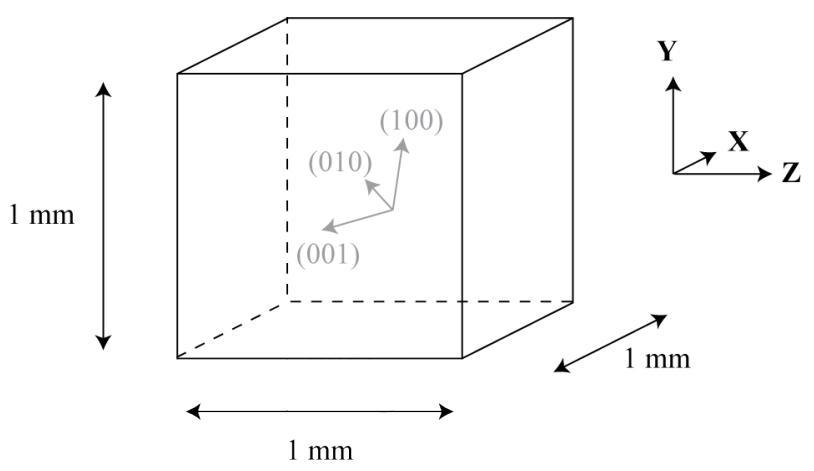

Figure 4.9. Single crystal configuration. (XYZ) denotes the global orthonormal coordinate systems. 
First, the applied (mechanical and hydrogen related) boundary conditions are $\forall$ presented; selected crystal orientations are then described, as are the used material parameters

$\mathrm{C}_{\mathrm{L}}(\mathrm{t}=0)=\mathrm{C}_{0}$.

\subsubsection{Boundary and initial conditions}

Mechanical loading is applied on a single crystal pre-charged with hydrogen.

\subsubsection{Mechanical boundary conditions}

Mechanical symmetry boundary conditions are applied on the bottom face of the cube, while a $0.05 \mathrm{~mm}$ displacement is applied to the top one (corresponding to an average strain of $5 \%$ in the $\mathbf{Y}$ direction), to allow to capture the effect of plasticity triggering on hydrogen repartition. The applied displacement rate is set to $0.05 \mathrm{~mm} / \mathrm{s}$ (corresponding to an applied strain rate of $5.10^{-2} \mathrm{~s}^{-1}$ ); this high value is expected to decrease the purely Fickian contribution $\varphi_{\mathrm{L}}$ in the global hydrogen flux, enhancing the $\varphi_{\mathrm{d}}$ one.

\subsubsection{Initial hydrogen concentration}

The sample is precharged in hydrogen so that, before any mechanical loading, $\mathrm{C}_{\mathrm{L}}=\mathrm{C}_{0}$ everywhere in the bulk, with $\mathrm{C}_{0}=2.084 \times 10^{21}$ atoms $/ \mathrm{m}^{3}$ (Johnson, 1974; Sofronis and McMeeking, 1989; Taha and Sofronis, 2001). Hydrogen-related symmetry conditions are applied on all external faces so as the normal hydrogen flux is zero (Figure 4.10).

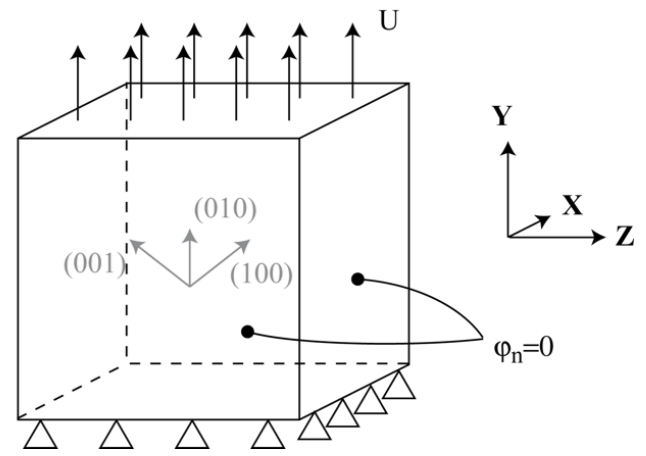

Figure 4.10. Single crystal configuration. $(X Y Z)$ denotes the global orthonormal coordinate systems. Displacement is applied along the $Y$ direction. 
Plastic strain on slip systems induced by the mechanical loading is expected to redistribute the hydrogen in the crystal, due to the concomitant effects of trapping and extra term $\varphi_{\mathrm{d}}$, and the subsequent $\mathrm{C}_{\mathrm{L}}$ heterogeneous distribution. In the whole section 4.5 , the contribution of the hydrostatic pressure to the global hydrogen flux has been neglected (i.e., $\mathrm{V}_{\mathrm{H}}$ has been set to 0 ).

\subsubsection{Crystal orientations}

To investigate the influence of slip system configurations on the hydrogen transport, two cases have been chosen for the macroscopic tensile direction Y - see Figure 4.10):

- $\quad[\overline{\mathbf{1 2 3}}]$ as $\mathrm{Y}$ direction, for which a single glide is expected $\left(\mathrm{n}^{\circ} 9\right.$, see Appendix 4.7, leading to $\boldsymbol{\varphi}_{d}=\boldsymbol{\varphi}_{d}^{9}$ ). To get $\boldsymbol{\varphi}_{\mathrm{d}}$ in the $\mathbf{X Y}$ plane, the $\mathbf{Z}$ vector is set to $\overline{\mathbf{1}} \overline{\mathbf{3}}$ : for such a coordinate system, $\mathbf{m}^{9} / /-0.78 \mathbf{X}+0.6 \mathbf{Y}$.

- $\quad[\mathbf{1 1 1}]$ as Y direction, where multiple slip systems are expected $\left(n^{\circ} 1\right.$ to 6, see Appendix 4.7). $\mathbf{Z}$ is set parallel to $\overline{\mathbf{1 1 0}}$.

\subsubsection{Results}

The results of the hydrogen map evolutions due to plastic strain on the two above described configurations are presented, with a particular focus on the $\overline{\mathbf{1 2 3}}$ direction.

\subsubsection{Traction along the $\overline{\mathbf{1} 23}$ direction}

On Figure 4.11 is reported the spatial repartition the total cumulated shear strain $\gamma$ and the one the slip system (9), $\gamma^{9}$, showing it is the only activated system, as expected from the computations of the Schmid factors computation in a pure tensile configuration (Appendix 4.7). 


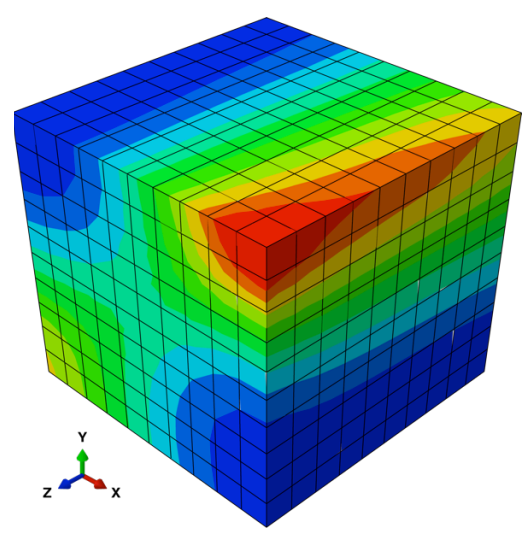

(a)

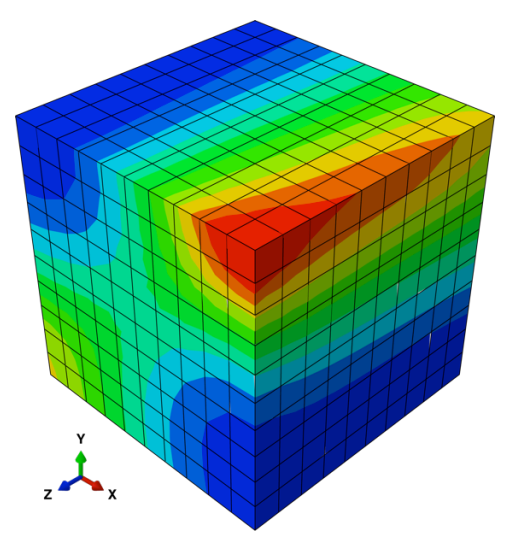

(b)

Figure 4.11. Comparison at the end of the mechanical loading of the (a) $\gamma$ and (b) $\gamma^{9}$ repartition maps.

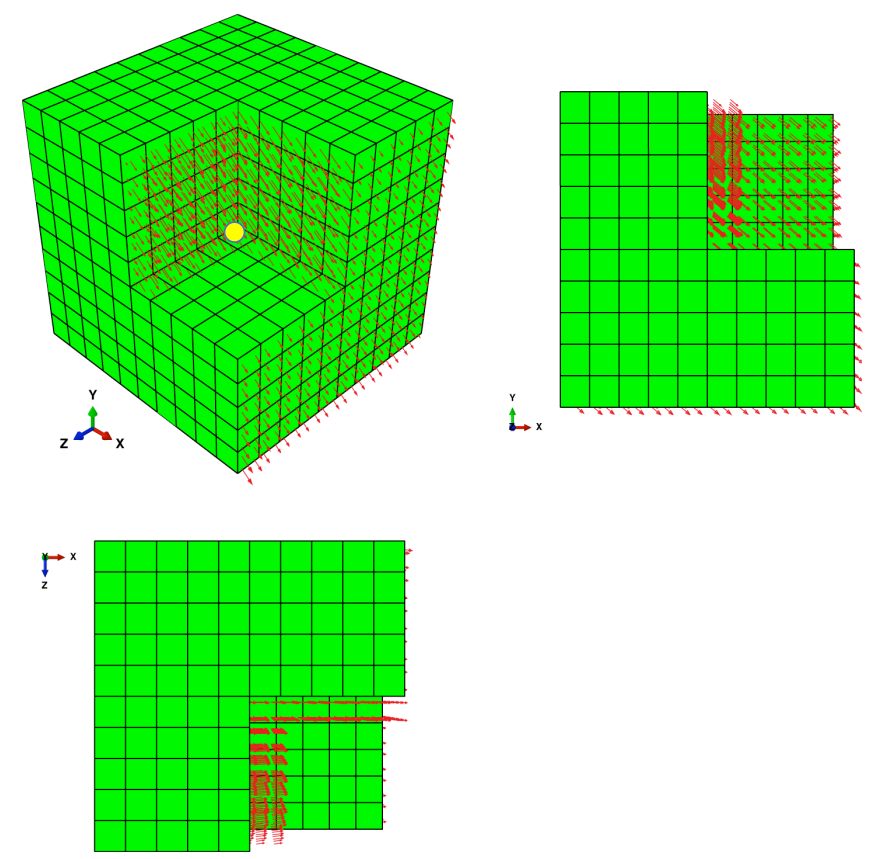

Figure 4.12. Visualization of the hydrogen flux $\varphi\left(\sim \varphi_{d}\right)$. It can be observed that, as expected, this flux is collinear to $\boldsymbol{m}^{9}$, in the $(\mathbf{X Y})$ plane. The yellow dot represents the central node. 
The hydrogen flux $\varphi=\varphi_{\mathrm{L}}+\varphi_{\mathrm{d}}$ induced by the single crystal deformation is shown on Figure 4.12, and appears to be connected to plasticity development, along the $\mathbf{m}^{9}$ direction.

It is worth noting that the purely Fickian contribution in $\varphi$ is negligible: $\left\|\varphi_{\mathrm{d}}\right\| / \mid \varphi \| \geq 99.1$, i.e $\varphi \sim \varphi_{\mathrm{d}}$. On Figure 4.13a is presented the evolution with time of $\|\varphi\|, \theta_{\mathrm{T}}, \theta_{\mathrm{L}}$ and $\dot{\gamma}^{9}$ on the central node (yellow dot on Figure 4.12), illustrating that an extra hydrogen transport appears as soon as $\dot{\gamma}^{9}$ is non zero. The related flux first evolved with $\dot{\gamma}^{9}, \theta_{\mathrm{T}}$ begin constant and equal to $1 . \theta_{\mathrm{L}}$ decreases continuously, because of that flux and the applied diffusion boundary conditions on the single crystal. When $\theta_{\mathrm{L}}$ becomes low enough, and due to the Oriani's expression (Equation [4.6]), $\theta_{\mathrm{T}}$ quickly decreases, and so does the hydrogen flux. The $\mathrm{C}_{\mathrm{L}}$ repartition in the single crystal is highly affected as illustrated on Figure 4.13b, and appears to be mainly localized on the faces pointed out by $\mathbf{m}^{9}$ (see Figure 4.12).

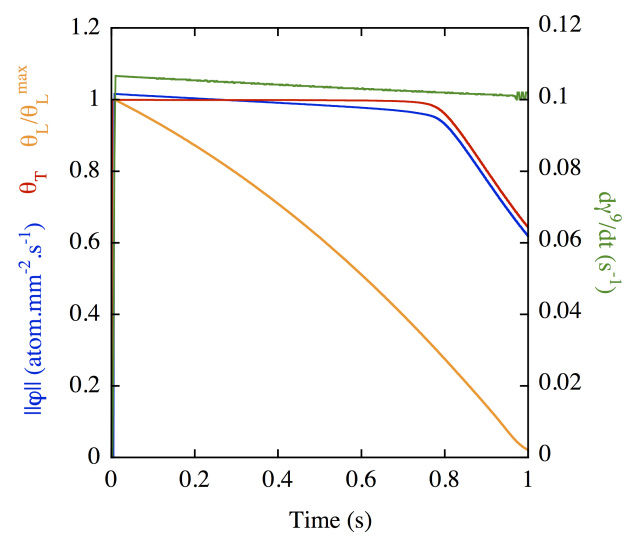

(a)

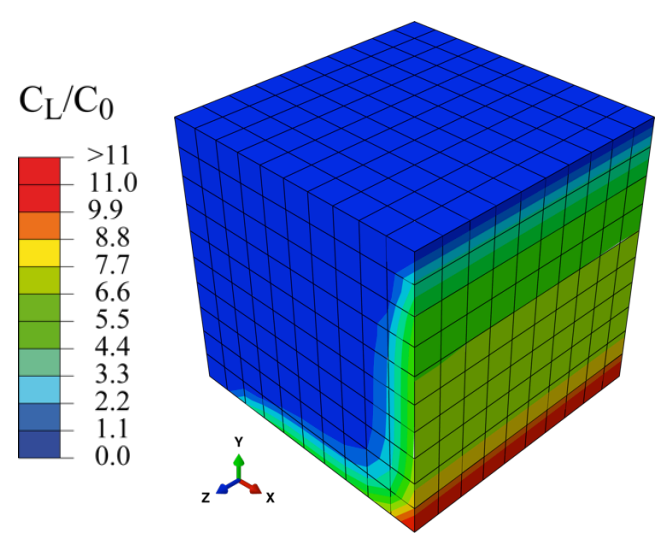

(b)

Figure 4.13. (a) Evolution with time of the hydrogen flux $\|\varphi\|_{6}$, the trapped and diffusive hydrogen site occupancy $\theta_{T}$ and $\theta_{L}$, and the slip rate $\dot{\gamma}^{9}$ at the center of the single crystal (yellow dot on Figure 4.12). $\theta_{L}^{\max }$ represents the $\theta_{L}$ value at $t=0$, which is equal to $2.46 \times 10^{-8}$. (b) Diffusive hydrogen repartition at $t=1 \mathrm{~s}$. 


\subsubsection{Traction along the 111 direction}

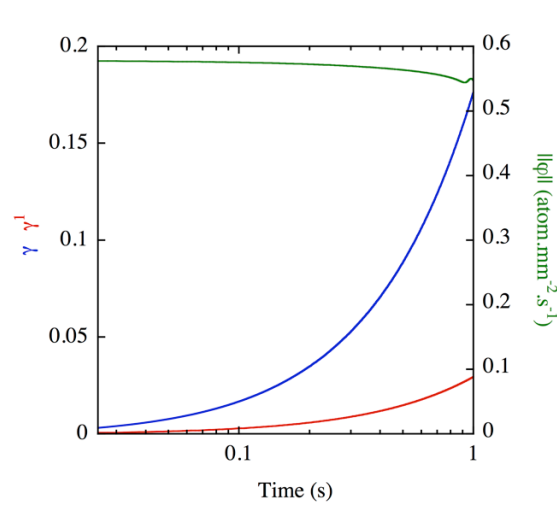

(a)

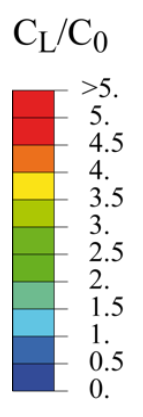

(b)

Figure 4.14. (a) Evolution with time of $\gamma, \gamma^{1}$ and $\|\varphi\|$, (b) $C_{L}$ repartition at $t=1 \mathrm{~s}$.

On Figure 4.14a are reported the evolution with time of $\gamma, \gamma^{1}$ and $\|\varphi\|$; in this configuration, $\left\|\varphi_{\mathrm{d}}\right\| / \mid \varphi \| \geq 98.5$ (the purely Fickian contribution is thus negligible, with $\left.\varphi \sim \varphi_{\mathrm{d}}\right)$.

It can be seen that $\gamma$ is six times greater than $\gamma^{1}$; in this symmetric orientation, six equivalent slip systems operate in this configuration ( $n^{\circ} 1$ to 6 ), with the same cumulated slip. In such a configuration, $\boldsymbol{\varphi}_{d} / / \sum_{\alpha=1}^{6} \boldsymbol{m}^{\alpha}=\sqrt{3} \boldsymbol{Y}$, which is consistent with Figure 4.14b: $C_{L}$ accumulates on the upper face of the sample, pointed out by the $\sum_{\alpha=1}^{6} \boldsymbol{m}^{\alpha}$ vector. Such redistribution indicates a potential acceleration of the hydrogen transport process towards the traction direction. 


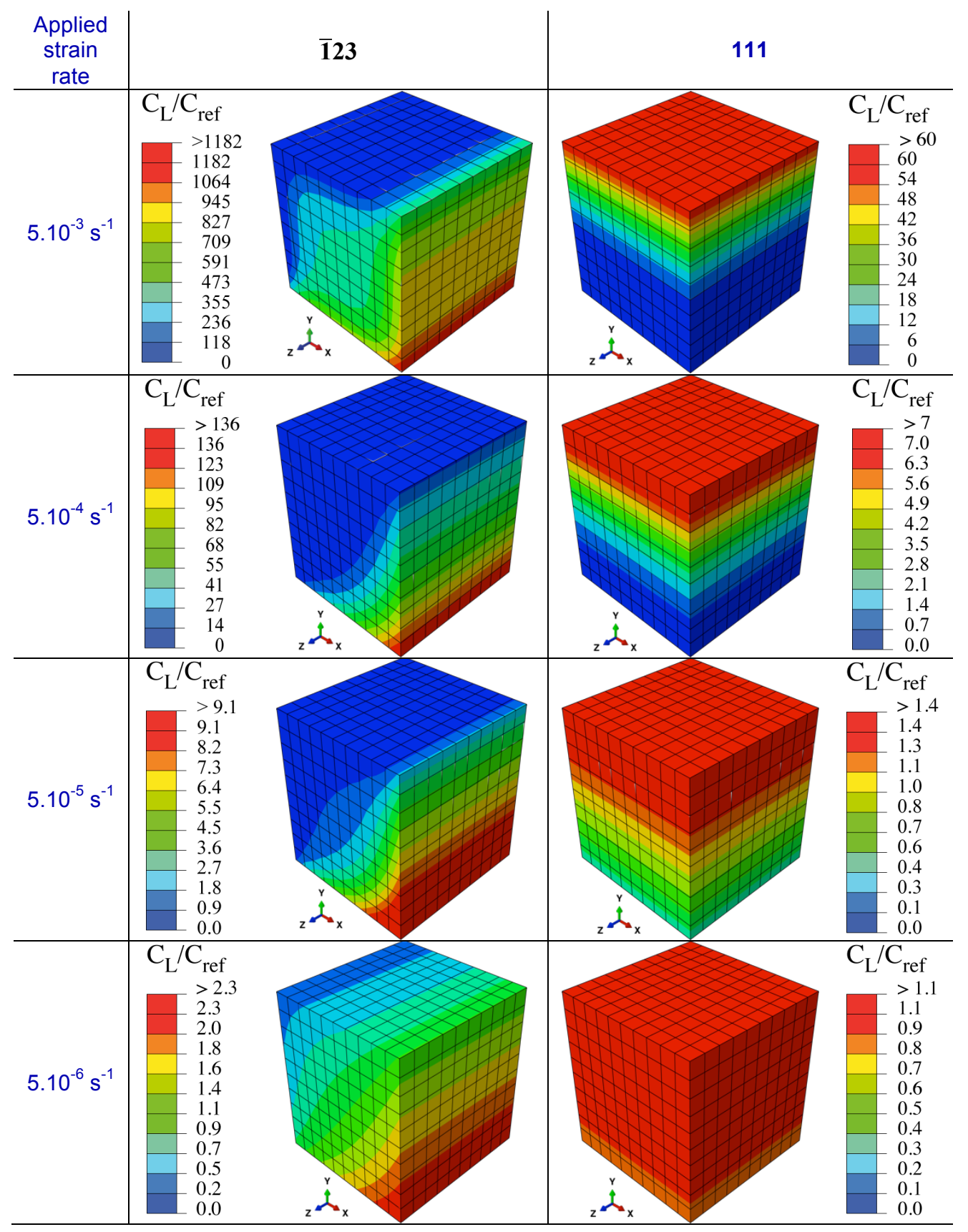


Figure 4.15. Dimensionless diffusive hydrogen repartition for the single crystals submitted to a displacement in the $\overline{\mathbf{1} 23}$ and 111 directions, for various applied strain rates. It has been checked that, if $\varphi_{d}=0, C_{L}=C_{\text {ref }}$ everywhere in the sample, for the two configurations.

\subsubsection{Influence of the applied strain rate}

Computations have been performed for various applied strain rates $\left(5.10^{-3}\right.$, $5.10^{-4}, 5.10^{-5}$ and $5.10^{-6} \mathrm{~s}^{-1}$ ), to exhibit the competition of between $\varphi_{\mathrm{L}}$ and $\varphi_{\mathrm{d}}$ in the two single crystals. The $\mathrm{C}_{\mathrm{L}} / \mathrm{C}_{\text {ref }}$ maps at the end of the mechanical loading are reported on Figure 4.15, in which $\mathrm{C}_{\text {ref }}$ denotes the homogeneous concentration at the end of the mechanical loading in the reference case, defined by $\varphi_{\mathrm{d}}=\mathbf{0}$.

\subsubsection{Consequences on hydrogen transport through a polycrystalline bar}

The above computations suggest that the $\varphi_{\mathrm{d}}$ contribution might have a significant impact on the global hydrogen transport process, depending on the single crystal orientation, the loading direction, and the applied strain rate. In [111] orientation, $\varphi_{\mathrm{d}}$ was shown to contribute to increase hydrogen transport in the tensile direction, whereas it is not the case for the $[\overline{\mathbf{1 2 3}}]$ orientation. Then at the polycrystal scale, these effects are expected to be influenced by the crystallographic texture of the polycrystal. 


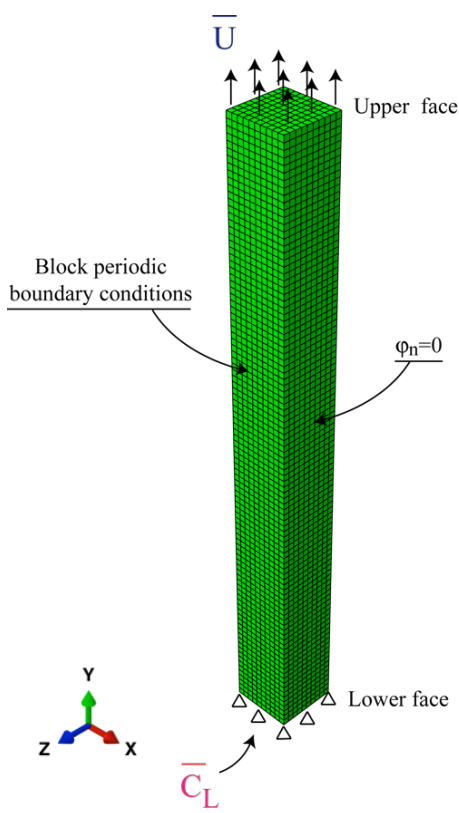

(a)

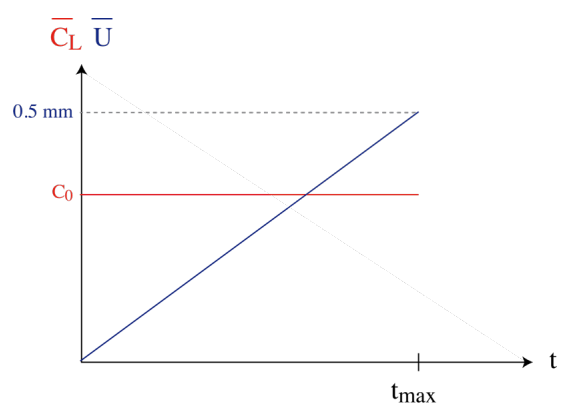

(b)

Figure 4.16. (a) Boundary conditions applied on the polycrystalline bar. (b) Temporal variation of $U(t)$.

To investigate this coupling, several computations have been performed on a parallelepipedic polycrystal $\left(1 \times 1 \times 10 \mathrm{~mm}^{3}\right)$, on which both displacement rate and hydrogen concentrations conditions have been imposed (Figure 4.16a).

The bar is meshed with 10000 tri-linear linear cubic elements, so that one finite element represents one grain, for the sake of simplicity and computation cost. Such an aggregate contains enough grains to be considered as a representative elementary volume for the transport and trapping process (Charles et al., 2017b).

The applied boundary conditions have been set as following (Figure 4.16b):

1. an hydrogen concentration $\bar{C}_{L}=C_{0}$ is instantaneously imposed on the polycrystal lower face, as well as a constant displacement rate $\dot{U}$ on the upper face, up to an average strain in the traction direction of 5\%;

2. on the lateral faces, uniform mixed-orthogonal boundary conditions are imposed (Charles et al., 2010; Salahouelhadj and Haddadi, 2010), as 
well as a zero normal hydrogen flux, to mimic mechanical and diffusion periodicity.

After all computations, the average $\left\langle\mathrm{C}_{\mathrm{L}}\right\rangle$ value of the diffusive hydrogen repartition on the bar upper face is extracted, following the same methodology than the one presented in (Charles et al., 2017b), and its evolution with the normalized time $\mathrm{t} / \mathrm{t}_{\max }$ is plotted, $\mathrm{t}_{\max }$ being the time needed to reach $5 \%$ strain.

Two parameters are focused on: the applied displacement rate (assuming an overall isotropic texture), and the texture (for a given applied displacement rate). To enhance the hydrogen transport by dislocations contribution to the total hydrogen flux $\varphi$, computed $\varphi_{\mathrm{d}}$ have been multiplied by 100 in the computations presented in the next section, following Dadfarnia (Dadfarnia et al., 2015).

\subsubsection{Influence of the strain rate for an isotropic texture}

The considered applied strain rates are the same than in the section 4.4.5.3. For each of them, two computations are made: one with the $\varphi_{\mathrm{d}}$ contribution, and one without. The $\left\langle\mathrm{C}_{\mathrm{L}}\right\rangle$ evolutions with time are plotted on Figure 4.17a.

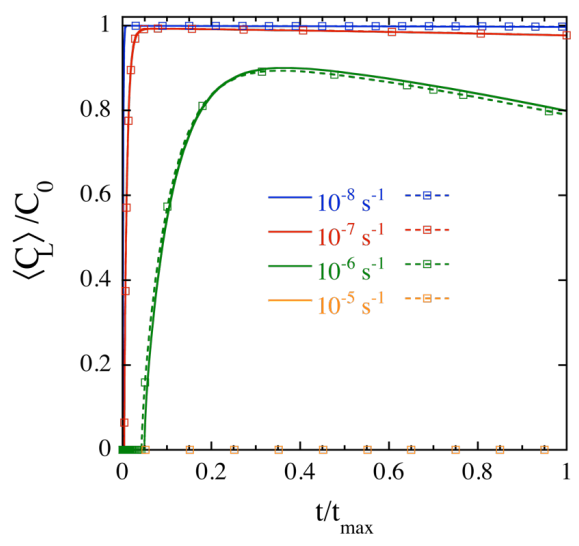

(a)

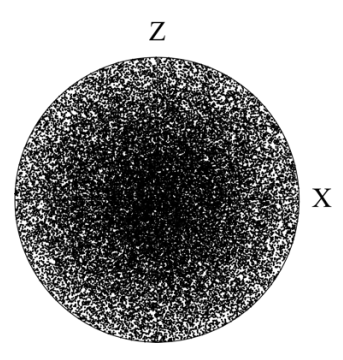

(b)

Figure 4.17. (a) Evolution of $\left\langle C_{L} / C_{0}\right\rangle$ on the upper face for all of the used strain rates considering the $\varphi_{d}$ contribution (dashed lines) or not (full lines). (b) Polycrystal $\langle 111\rangle$ pole figures. The decreases of $\left\langle C_{L} / C_{0}\right\rangle$ for an applied strain rate of $10^{-6} \mathrm{~s}^{-1}$ is due to the increase of trap density due to plastic strain development (see (Benannoune et al., 2018)).

The main information extracted from these computations is that the $\varphi_{\mathrm{d}}$ contribution has, in average, negligible effect on the global hydrogen transport 
process, recalling that this flux has been multiplied by 100 in the Figure 4.17a results. Such a result might be qualitatively explained by a statistical effect of the grain orientations over the polycrystal: diffusion acceleration due to a well-oriented grain (e.g, a $\mathbf{1 1 1}$ one) is counter-balanced by a bad oriented one (e.g. a $\overline{\mathbf{1} 23}$ one). However this is not the case for non-isotropic textures.

\subsubsection{Texture influence}

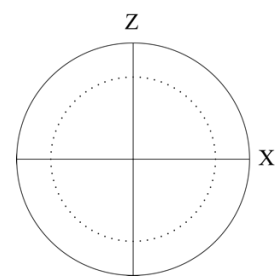

(a)

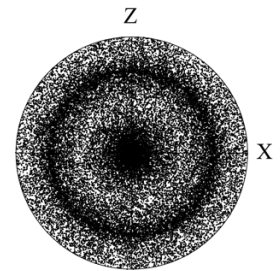

(e)

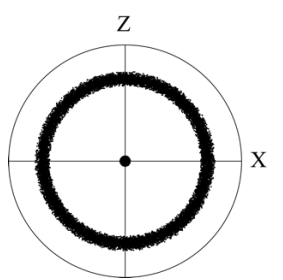

(b)

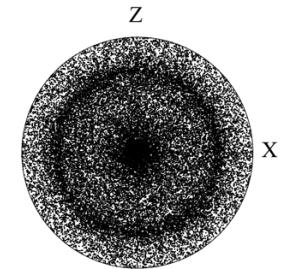

(f)

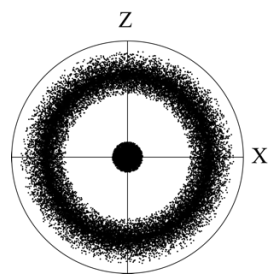

(c)

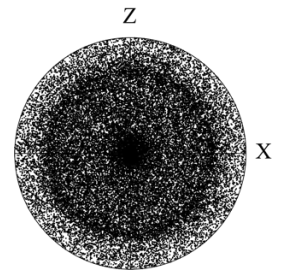

(g)

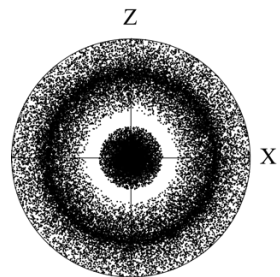

(d)

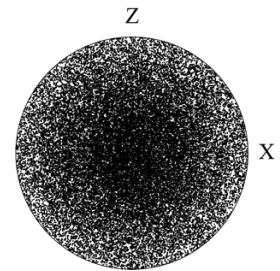

(h)

Figure 4.18. (a-g) considered (111) fiber textures with decreasing sharpness. (h) corresponds to the isotropic case of Figure $4.17 \mathrm{~b}$. For case (a) computations were performed with and without any transport by dislocations. 


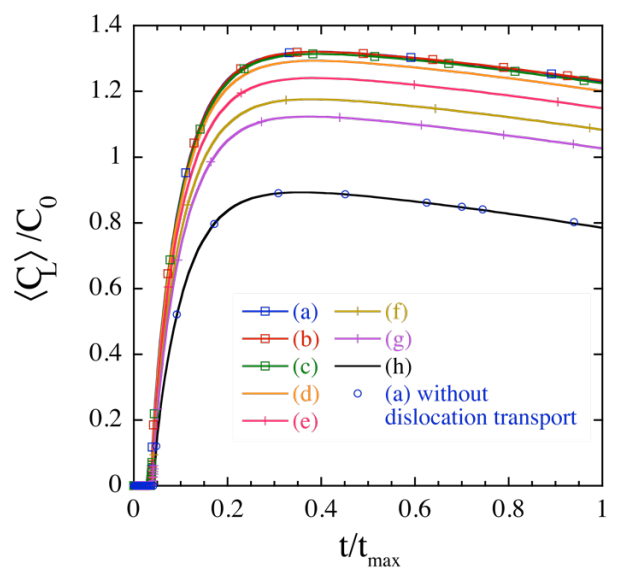

Figure 4.19. $\left\langle C_{L}\right\rangle$ evolution with time on the polycrystal upper face for different textures. The isotropic texture results correspond to the one plotted on Figure 4.17b.

To exhibit the texture influence on the hydrogen transport process, and based on the results obtained on [111] single crystal in section 4.4.5.2, several 111 fibers textures with $\mathbf{Y}$ axis have been considered, as shown in Figure 4.18. These textures have been generated considering a given scattering around a fixed orientation set. The applied strain rate was $10^{-6} \mathrm{~s}^{-1}$, as from Figure 4.17 the effect of plastic strain on the apparent hydrogen diffusion was the most evident for this value. $\left\langle\mathrm{C}_{\mathrm{L}}\right\rangle$ results on the polycrystal upper face are plotted on Figure 4.19 for all computations.

The results are similar for the sharpest fiber textures (a-c), but significantly differ from the isotropic case (h). Between the two, it can be noticed that the effect of the texture remains pronounced, even for textures with apparent moderate fiber reinforcements (see the differences between $(\mathrm{g})$ and $(\mathrm{h})$ for example)

It can also be underlined that if no extra hydrogen transport is considered (black line (h) and blue dots on Figure 4.19), no differences appears in the $\left\langle\mathrm{C}_{\mathrm{L}}\right\rangle$ evolution with time, showing that there is, in average, no influence of the polycrystal texture on the hydrogen transport and trapping process, as for the isotropic texture. For the chosen configurations, the equivalent plastic strain state repartition appears to be statistically equivalent in the samples (see Figure 4.20), and therefore the effect of crystal orientations on trapping is limited effect since it is controlled by the local equivalent plastic strain. More precise accounting for the trapping process at the slip system scale would be needed to improve the modeling, which was out of scope of the present study. 


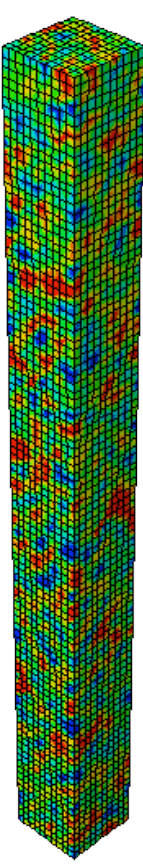

(a)
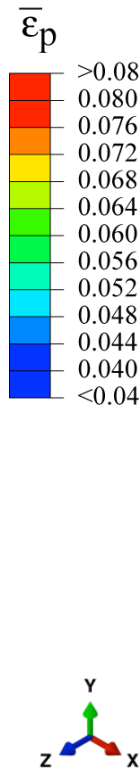

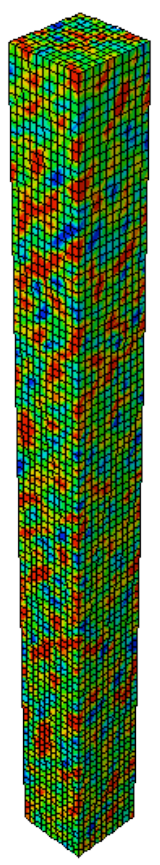

(b)

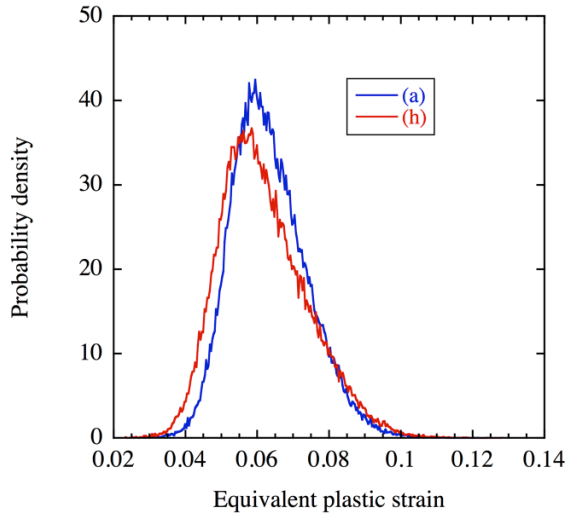

(c)

Figure 4.20. Equivalent plastic strain repartition in the polycrystal at the end of the mechanical loading with the textures of (a) Figure 4.18a and of (b) Figure 4.18h. (c) Statistical distribution of the equivalent plastic strain in the two samples.

\subsection{Conclusion}

In this chapter, we have focused on the hydrogen transport and trapping relationship, while considered at the crystal and component scales. We have linked, especially, the average time-to-diffusion thought deformed samples and the one along with an equivalent homogeneous sample. As we have shown, the hydrogen trapping in single crystal and its subsequent transport have non-trivial consequences at the component scale due to the polycrystal features (mechanical anisotropy, slip system, texture,...). The link we are developing under Abaqus software, using a fully mechanical-hydrogen transport and trapping resolution scheme, might help to redefine the global material parameters (as the effective diffusion coefficient) or evolution laws (as the diffusion equation), at the macro-scale. 
The polycrystal scale in conjunction with crystal plasticity provides a convenient frame for studying the material-hydrogen interactions, and especially, the interplay between defects (as vacancies or dislocations) and hydrogen transport and trapping.

In the case of hydrogen dragging by dislocations, or any relevant phenomenon at that scale, as proposed in the literature, it is possible to include in computations the effect of a given crystal structure and material texture, opening the path to texture engineering for decreasing (or increasing) the transport process. Of course, the used formalism has to be challenged, and, especially, modified to account for the specificities of that scale (e.g., using the dislocation density as a parameter for the trap density). Further developments are thus needed, provided by both models and experiments at lower scales, to improve the description of the hydrogen and material interactions and to test assumptions extracted from experiments.

Abaqus, 3, 10, 13, 35

CPFEM, 4, 5, 6, See

Polycrystalline, See Crystal Plasticity

Crystal Plasticity, 3, 6, 7, 10, 36, See CPFEM

Diffusion, 3, 4, 5, 6, 9, 10, 11, 12, 13, 14, 19, 26, 32, 33, 34, 35,

See Transport

Dislocation, 3, 6, 7, 19, 20, 21, 36

FE, 3, See Finite Element

\section{Finite Element, 3}

Hydrogen, 2, 3, 4, 5, 6, 7, 8, 9, 12 , $14,15,18,19,20,21,22,23$, $24,25,26,27,28,30,31,32$, $33,34,35,36$

Metal: Aluminum, 2, 5, 6;

Copper, 5; Iron, 2, 3, 6, 7, 11, 12; Nickel, 2, 5, 6, 19;

Polycrystal, 4; Single Crystal,
$2,3,6,22,23,26,27,30,34$, 35; Steel, 3, 4, 5, 6; Tungsten, 3,4

Multi-scale, 2, 6

Polycrystalline, 4, 12, 13, 15, 16, 17, 18, 19, 20, 30, 31, See CPFEM

Scale Transition, 4, 6, 19

Transport, 3, 4, 5, 6, 7, 8, 9, 10, $12,14,15,16,17,18,19,20$, $21,22,24,26,28,30,31,32$, 33, 34, 35, 36, See Diffusion

Trapping, 3, 4, 5, 6, 7, 8, 9, 10, $11,12,14,15,16,17,18,19$, $24,31,34,35,36$

User Subroutine, 10, 13 
4.7. Appendix: Numbering of the slip systems in the UMAT

\begin{tabular}{|c|c|c|c|c|}
\hline \multirow{2}{*}{$\begin{array}{c}\text { Slip system } \\
\text { number }\end{array}$} & \multirow{2}{*}{ Slip plane } & \multirow{2}{*}{$\begin{array}{l}\text { Slip } \\
\text { direction }\end{array}$} & \multicolumn{2}{|c|}{$\begin{array}{c}\text { Schmid factors for a tensile test } \\
\text { along the direction }\end{array}$} \\
\hline & & & $\overline{1} 23$ & 111 \\
\hline 1 & $\left(\begin{array}{llll}0 & 0 & 1 & 1\end{array}\right)$ & {$\left[\begin{array}{lll}1 & -1 & 1\end{array}\right]$} & 0.00 & 0.27 \\
\hline 2 & $\left(\begin{array}{lll}0 & 1 & 1\end{array}\right)$ & {$\left[\begin{array}{lll}1 & 1 & -1\end{array}\right]$} & -0.29 & 0.27 \\
\hline 3 & $\left(\begin{array}{llll}1 & 0 & 1\end{array}\right)$ & {$\left[\begin{array}{lll}-1 & 1 & 1\end{array}\right]$} & 0.35 & 0.27 \\
\hline
\end{tabular}




\begin{tabular}{|c|c|c|c|c|c|}
\hline 4 & $\left(\begin{array}{lll}1 & 0 & 1\end{array}\right)$ & {$\left[\begin{array}{lll}1 & 1 & -1\end{array}\right]$} & -0.12 & 0.27 \\
\hline 5 & $\left(\begin{array}{lll}1 & 1 & 0\end{array}\right)$ & {$\left[\begin{array}{lll}-1 & 1 & 1\end{array}\right]$} & 0.17 & 0.27 \\
\hline 6 & $\left(\begin{array}{lll}1 & 1 & 0\end{array}\right)$ & {$\left[\begin{array}{lll}1 & -1 & 1\end{array}\right]$} & 0.00 & 0.27 \\
\hline 7 & $\left(\begin{array}{lll}0 & -1 & 1\end{array}\right)$ & {$\left[\begin{array}{lll}1 & 1 & 1\end{array}\right]$} & 0.12 & 0 \\
\hline 8 & $\left(\begin{array}{lll}0 & -1 & 1\end{array}\right)$ & {$\left[\begin{array}{lll}-1 & 1 & 1\end{array}\right]$} & 0.17 & 0 \\
\hline 9 & $\left(\begin{array}{lll}1 & 0 & -1\end{array}\right)$ & {$\left[\begin{array}{lll}1 & 1 & 1\end{array}\right]$} & -0.47 & 0 \\
\hline 10 & $\left(\begin{array}{lll}1 & 0 & -1\end{array}\right)$ & {$\left[\begin{array}{lll}1 & -1 & 1\end{array}\right]$} & 0.00 & 0 \\
\hline 11 & $\left(\begin{array}{lll}-1 & 1 & 0\end{array}\right)$ & {$\left[\begin{array}{lll}1 & 1 & 1\end{array}\right]$} & 0.35 & 0 \\
\hline 12 & $\left(\begin{array}{lll}-1 & 1 & 0\end{array}\right)$ & {$\left[\begin{array}{lll}1 & 1 & -1\end{array}\right]$} & -0.17 & 0 \\
\hline
\end{tabular}

Table 4.5. Slip plane numbering (Huang 1991) and Schmid factors in specific configurations

\subsection{References}

Albrecht, J., Bernstein, I. M., and Thompson, A. W. (1982). Evidence for dislocation transport of hydrogen in aluminum. Metallurgical Transactions A, 13, 811-820. doi: 10.1007/BF02642394.

Alvaro, A., Thue Jensen, I., Kheradmand, N., Løvvik, O. M., and Olden, V. (2015). Hydrogen embrittlement in nickel, visited by first principles modeling, cohesive zone simulation and nanomechanical testing. International Journal of Hydrogen Energy, 40, 16892-16900. doi: 10.1016/j.ijhydene.2015.06.069.

Asaro, R. J. (1983). Micromechanics of crystals and polycrystals. Advances in Applied Mechanics, 23, 1-115. doi: 10.1016/S0065-2156(08)70242-4.

Aubert, I., Bouhattate, J., Charles, Y., Couvant, T., Dhondt, M., Duhamel, C., Fregonese, M., Gaspérini, M., Hénaff, G., Metsue, A., and Saintier, N. (2019). Local-scale modeling of plasticity-environment interactions. In Mechanics Microstructure - Corrosion Coupling. Elsevier, pp. 413-438. doi: 10.1016/B978-178548-309-7.50018-1.

Aubert, I., Saintier, N., Olive, J.-M., and Plessier, F. (2016). A methodology to obtain data at the slip-band scale from atomic force microscopy observations and crystal plasticity simulations. Application to hydrogen-induced slip localization on AISI 316L stainless steel. Acta Materialia, 104, 9-17. doi: 10.1016/j.actamat. 2015.11.042.

Ayadi, S., Charles, Y., Gaspérini, M., Caron Lemaire, I., and Da Silva Botelho, T. (2017). Effect of loading mode on blistering in iron submitted to plastic prestrain before hydrogen cathodic charging. International Journal of Hydrogen Energy, 42, 10555-10567. doi: 10.1016/j.ijhydene.2017.02.048. 
Bal, B., Koyama, M., Canadinc, D., Gerstein, G., Maier, H., and Tsuzaki, K. (2017). On the utility of crystal plasticity modeling to uncover the individual roles of microdeformation mechanisms on the work hardening response of Fe-23Mn-0.5C TWIP steel in the presence of hydrogen. Journal of Engineering Materials and Technology, 140, 031002. doi: 10.1115/1.4038801.

Barnoush, A., Dake, J., Kheradmand, N., and Vehoff, H. (2010). Examination of hydrogen embrittlement in FeAl by means of in situ electrochemical micropillar compression and nanoindentation techniques. Intermetallics, 18, 1385-1389. doi: 10.1016/j.intermet.2010.01.001.

Barrer, R. M. (1951). Diffusion in and through Solids. Cambridge University Press, Cambridge.

Barrera, O., Bombac, D., Chen, Y., Daff, T. D., Galindo-Nava, E., Gong, P., Haley, D., Horton, R., Katzarov, I., Kermode, J. R., Liverani, C., Stopher, M., and Sweeney, F. (2018). Understanding and mitigating hydrogen embrittlement of steels: a review of experimental, modelling and design progress from atomistic to continuum. Journal of Materials Science, 53, 6251-6290. doi: 10.1007/s10853-0171978-5.

Benabou, L. (2019). Coupled stress-diffusion modelling of grain boundary segregation and dynamic embrittlement in a copper alloy. Modelling and Simulation in Materials Science and Engineering, 27, 045007. doi: 10.1088/1361$651 X / a b 1624$.

Benannoune, S., Charles, Y., Mougenot, J., and Gaspérini, M. (2018). Numerical simulation of the transient hydrogen trapping process using an analytical approximation of the $\mathrm{McNabb}$ and Foster equation. International Journal of Hydrogen Energy, 43, 9083-9093. doi: 10.1016/j.ijhydene.2018.03.179.

Benannoune, S., Charles, Y., Mougenot, J., Gaspérini, M., and De Temmerman, G. (2019a). Multidimensional finite element simulations of the diffusion and trapping of hydrogen in Plasma- Facing Components including thermal expansion. Physica Scripta, minor review.

Benannoune, S., Charles, Y., Mougenot, J., Gaspérini, M., and De Temmerman, G. (2019b). Numerical simulation by finite element modelling of diffusion and transient hydrogen trapping processes in plasma facing components. Nuclear Materials and Energy, 19, 42-46. doi: 10.1016/j.nme.2019.01.023.

Benedetti, I., Gulizzi, V., and Milazzo, A. (2018). Grain-boundary modelling of hydrogen assisted intergranular stress corrosion cracking. Mechanics of Materials, 117, 137-151. doi: 10.1016/j.mechmat.2017.11.001.

Berkowitz, B. J. and Heubaum, F. H. (1983). Dislocation transport of hydrogen in steel. In Atomistics of Fracture, Latanison, R. M. and Pickens, J. R. (eds). Springer US, Boston, MA, pp. 823-827. doi: 10.1007/978-1-4613-3500-9_31. 
Birnbaum, H. K. and Sofronis, P. (1994). Hydrogen-enhanced localized plasticity a mechanism for hydrogen-related fracture. Materials Science and Engineering: A, 176, 191-202. doi: 10.1016/0921-5093(94)90975-X.

Bogkris, J. O., Beck, W., Genshaw, M. A., Subramanyan, P. K., and Williams, F. S. (1971). The effect of stress on the chemical potential of hydrogen in iron and steel. Acta Metallurgica, 19, 1209-1218. doi: 10.1016/0001-6160(71)90054-X.

Cailletaud, G. (2009). Une introduction à la plasticité cristalline interactions avec l'environnement. In Presented at the Mécanismes et Mécanique des Interactions Plasticité - Environnement, Viguier, B. (ed). EDP Sciences, Argelès-sur-Mer, France, pp. 81-115. doi: 10.1051/ptox/2009008.

Charles, Y., Estevez, R., Bréchet, Y., and Maire, E. (2010). Modelling the competition between interface debonding and particle fracture using a plastic strain dependent cohesive zone. Engineering Fracture Mechanics, 77, 705-718. doi: 10.1016/j.engfracmech.2009.11.012.

Charles, Y., Gaspérini, M., Ardon, K., Ayadi, S., Benannoune, S., and Mougenot, J. (2018). Adaptation of hydrogen transport models at the polycrystal scale and application to the U-bend test. Procedia Structural Integrity, 13, 896-901. doi: 10.1016/j.prostr.2018.12.169.

Charles, Y., Gaspérini, M., Disashi, J., and Jouinot, P. (2012). Numerical modeling of the Disk Pressure Test up to failure under gaseous hydrogen. Journal of Materials Processing Technology, 212, 1761-1770. doi: 10.1016/j.jmatprotec.2012.03.022.

Charles, Y., Gaspérini, M., Fagnon, N., Ardon, K., and Duhamel, A. (2019). Finite element simulation of hydrogen transport during plastic bulging of iron submitted to gaseous hydrogen pressure. Engineering Fracture Mechanics, accepted.

Charles, Y., Nguyen, T. H., and Gaspérini, M. (2017a). FE simulation of the influence of plastic strain on hydrogen distribution during an U-bend test. International Journal of Mechanical Sciences, 120, 214-224. doi: 10.1016/ j.ijmecsci.2016.11.017.

Charles, Y., Nguyen, T. H., and Gaspérini, M. (2017b). Comparison of hydrogen transport through pre-deformed synthetic polycrystals and homogeneous samples by finite element analysis. International Journal of Hydrogen Energy, 42, 2033620350. doi: 10.1016/j.ijhydene.2017.06.016.

Cheng, X., Zhang, Z., Liu, W., and Wang, X. (2013). Direct observation of hydrogen-trapping sites in newly developed high-strength mooring chain steel by atom probe tomography. Progress in Natural Science: Materials International, 23, 446-452. doi: 10.1016/j.pnsc.2013.06.005.

Dadfarnia, M., Martin, M. L., Nagao, A., Sofronis, P., and Robertson, I. M. (2015). Modeling hydrogen transport by dislocations. Journal of the Mechanics and Physics of Solids, 78, 511-525. doi: 10.1016/j.jmps.2015.03.002.

Dederichs, P. H. and Schroeder, K. (1978). Anisotropic diffusion in stress fields. Physical Review B, 17, 2524-2536. doi: 10.1103/PhysRevB.17.2524. 
Deng, Y. and Barnoush, A. (2018). Hydrogen embrittlement revealed via novel in situ fracture experiments using notched micro-cantilever specimens. Acta Materialia, 142, 236-247. doi: 10.1016/j.actamat.2017.09.057.

Djukic, M. B., Bakic, G. M., Zeravcic, V. S., Sedmak, A., and Rajicic, B. (2016). Hydrogen embrittlement of industrial components: prediction, prevention, and models. Corrosion, 72, 943-961. doi: 10.5006/1958.

Djukic, M. B., Bakic, G. M., Zeravcic, V. S., Sedmak, A., and Rajicic, B. (2019). The synergistic action and interplay of hydrogen embrittlement mechanisms in steels and iron: localized plasticity and decohesion. Engineering Fracture Mechanics, 216, 106528. doi: j.engfracmech.2019.106528.

Donovan, J. A. (1976). Accelerated evolution of hydrogen from metals during plastic deformation. Metallurgical Transactions A, 7, 1677-1683. doi: 10.1007/ BF02817885.

Ehlers, F. J. H., Seydou, M., Tingaud, D., Maurel, F., Charles, Y., and Queyreau, S. (2016). Ab initio determination of the traction-separation curve for a metal grain boundary: a critical assessment of strategies. Modelling and Simulation in Materials Science and Engineering, 24, 085014. doi: 10.1088/0965-0393/24/8/085014.

Ehlers, F. J. H., Seydou, M., Tingaud, D., Maurel, F., Queyreau, S., and Charles, Y. (2017). Ab initio studies of two Al grain boundaries subjected to mixed tension/shear mode loading: how shear may promote breakage. Modelling and Simulation in Materials Science and Engineering, 25, 064001. doi: 10.1088/1361$651 x / a a 7496$.

Evers, S., Senöz, C., and Rohwerder, M. (2013). Hydrogen detection in metals: a review and introduction of a Kelvin probe approach. Science and Technology of Advanced Materials, 14, 014201. doi: 10.1088/1468-6996/14/1/014201.

Fallahmohammadi, E., Bolzoni, F., and Lazzari, L. (2013). Measurement of lattice and apparent diffusion coefficient of hydrogen in X65 and F22 pipeline steels. International Journal of Hydrogen Energy, 38, 2531-2543. doi: 10.1016/j.jihydene. 2012.11.059.

Franciosi, P., Le, L. T., Monnet, G., Kahloun, C., and Chavanne, M. H. (2015). Investigation of slip system activity in iron at room temperature by SEM and AFM in-situ tensile and compression tests of iron single crystals. International Journal of Plasticity, 65, 226-249. doi: 10.1016/j.ijplas.2014.09.008.

Fu, B., Qiu, M., Cui, J., Li, M., and Hou, Q. (2018). The trapping and dissociation process of hydrogen in tungsten vacancy: a molecular dynamics study. Journal of Nuclear Materials, 508, 278-285. doi: 10.1016/j.jnucmat.2018.05.065.

Ghosh, G., Rostron, P., Garg, R., and Panday, A. (2018). Hydrogen induced cracking of pipeline and pressure vessel steels: a review. Engineering Fracture Mechanics, 199, 609-618. doi: j.engfracmech.2018.06.018. 
Griesche, A., Dabah, E., Kannengiesser, T., Kardjilov, N., Hilger, A., and Manke, I. (2014). Three-dimensional imaging of hydrogen blister in iron with neutron tomography. Acta Materialia, 78, 14-22. doi: 10.1016/j.actamat.2014.06.034.

$\mathrm{Gu}, \mathrm{Y}$. and El-Awady, J. A. (2018). Quantifying the effect of hydrogen on dislocation dynamics: a three-dimensional discrete dislocation dynamics framework. Journal of the Mechanics and Physics of Solids, 112, 491-507. doi: 10.1016/j.jmps.2018.01.006.

Hassan, H. U., Govind, K., and Hartmaier, A. (2018). Micromechanical modelling of coupled crystal plasticity and hydrogen diffusion. Philosophical Magazine, 99, 92-115. doi: 10.1080/14786435.2018.1530466.

Hirth, J. P. (1980). Effects of hydrogen on the properties of iron and steel. Metallurgical Transactions A, 11, 861-890. doi: 10.1007/BF02654700.

Hirth, J. P. and Johnson, H. H. (1983). On the transport of hydrogen by dislocations. In Atomistics of Fracture, Latanison, R. M. and Pickens, J. R. (eds). Springer US, Boston, MA, pp. 771-787. doi: 10.1007/978-1-4613-3500-9_26.

Huang, Y. (1991). A user-material subroutine incorporating single crystal plasticity in the ABAQUS finite element program. Mech Report 178, Cambridge, MA.

Hwang, C. and Bernstein, I. M. (1983). A demonstration of dislocation transport of hydrogen in iron. Scripta Metallurgica, 17, 1299-1304. doi: 10.1016/00369748(83)90220-X.

Hwang, C. and Bernstein, I. M. (1986). Dislocation transport of hydrogen in iron single crystals. Acta Metallurgica, 34, 1001-1010. doi: 10.1016/00016160(86)90209-9.

Ilin, D. N., Kutsenko, A. A., Tanguy, D., and Olive, J.-M. (2016). Effect of grain boundary trapping kinetics on diffusion in polycrystalline materials: hydrogen transport in Ni. Modelling and Simulation in Materials Science and Engineering, 24, 035008. doi: 10.1088/0965-0393/24/3/035008.

Ilin, D. N., Saintier, N., Olive, J.-M., Abgrall, R., and Aubert, I. (2014). Simulation of hydrogen diffusion affected by stress-strain heterogeneity in polycrystalline stainless steel. International Journal of Hydrogen Energy, 39, 2418-2422. doi: http://dx.doi.org/10.1016/j.ijhydene.2013.11.065.

Jiang, D. E. and Carter, E. A. (2004a). Diffusion of interstitial hydrogen into and through bec $\mathrm{Fe}$ from first principles. Physical Review B, 70, 064102. doi: 10.1103/PhysRevB.70.064102.

Jiang, D. E. and Carter, E. A. (2004b). First principles assessment of ideal fracture energies of materials with mobile impurities: implications for hydrogen embrittlement of metals. Acta Materialia, 52, 4801-4807. doi: 10.1016/ j.actamat.2004.06.037. 
Johnson, H. H. (1974). Hydrogen gas embrittlement. In Presented at the 7th International conference on the effects of hydrogen on materials properties and selection and structural design, Thompson, A. W. and Bernstein, I. M. (eds). Cornell University, Ithaca, NY, Champion, PA, pp. 35-49.

Johnson, H. H. (1988). Hydrogen in iron. Metallurgical and Materials Transactions $B, 19,691-707$. doi: 10.1007/BF02650189.

Jothi, S., Croft, T. N., and Brown, S. G. R. (2014). Influence of grain boundary misorientation on hydrogen embrittlement in bi-crystal nickel. International Journal of Hydrogen Energy, 39, 20671-20688. doi: 10.1016/j.ijhydene.2014.07.020.

Jothi, S., Croft, T. N., and Brown, S. G. R. (2015a). Modelling the influence of microstructural morphology and triple junctions on hydrogen transport in nanopolycrystalline nickel. Composites Part B: Engineering, 75, 104-118. doi: 10.1016/j.compositesb.2014.09.042.

Jothi, S., Croft, T. N., and Brown, S. G. R. (2015b). Multiscale multiphysics model for hydrogen embrittlement in polycrystalline nickel. Journal of Alloys and CompoundsJournal of Alloys and Compounds, 645, S500-S504. doi: 10.1016/j.jallcom.2014.12.073.

Jothi, S., Croft, T. N., Wright, L., Turnbull, A., and Brown, S. G. R. (2015c). Multiphase modelling of intergranular hydrogen segregation/trapping for hydrogen embrittlement. International Journal of Hydrogen Energy, 40, 15105-15123. doi: 10.1016/j.ijhydene.2015.08.093.

Koyama, M., Rohwerder, M., Tasan, C. C., Bashir, A., Akiyama, E., Takai, K., Raabe, D., and Tsuzaki, K. (2017). Recent progress in microstructural hydrogen mapping in steels: quantification, kinetic analysis, and multi-scale characterisation. Materials Science and Technology, 469, 1-16. doi: 10.1080/02670836. 2017.1299276.

Krom, A. H. M. and Bakker, A. D. (2000). Hydrogen trapping models in steel. Metallurgical and Materials Transactions B, 31, 1475-1482. doi: 10.1007/s11663000-0032-0.

Krom, A. H. M., Koers, R. W. J., and Bakker, A. D. (1999). Hydrogen transport near a blunting crack tip. Journal of the Mechanics and Physics of Solids, 47, 971-992. doi: http://dx.doi.org/10.1016/S0022-5096(98)00064-7.

Kumar, R., Meena, D., and Mahajan, D. K. (2019). Modelling of fatigue crack initiation in hydrogen charged polycrystalline nickel. Procedia Structural Integrity, 14, 668-675. doi: 10.1016/j.prostr.2019.05.083.

Kumnick, A. J. and Johnson, H. H. (1980). Deep trapping states for hydrogen in deformed iron. Acta Metallurgica, 28, 33-39. doi: 10.1016/0001-6160(80)90038-3.

Kysar, J. W. (1991). Addendum to "A user-material subroutine incorporating single crystal plasticity in the ABAQUS finite element program". Mech Report 178, Cambridge, MA. 
Lacaille, V., Morel, C., Feulvarch, E., Kermouche, G., and Bergheau, J. M. (2014). Finite element analysis of the grain size effect on diffusion in polycrystalline materials. Computational Materials Science, 95, 187-191. doi: 10.1016/ j.commatsci.2014.07.026.

Le, L. T. (2013). Etude par essais in situ MEB et AFM sur monocristaux des mécanismes de glissement à température ambiante de la ferrite de pureté commerciale. Université Paris 13, Sorbonne Paris Cité, Villetaneuse, France.

Legrand, E., Bouhattate, J., Feaugas, X., and Garmestani, H. (2012). Computational analysis of geometrical factors affecting experimental data extracted from hydrogen permeation tests: II - consequences of trapping and an oxide layer. International Journal of Hydrogen Energy, 37, 13574-13582. doi: 10.1016/j.ijhydene. 2012.06.043.

Legrand, E., Bouhattate, J., Feaugas, X., Touzain, S., Garmestani, H., Khaleel, M., and Li, D. S. (2013). Numerical analysis of the influence of scale effects and microstructure on hydrogen diffusion in polycrystalline aggregates. Computational Materials Science, 71, 1-9. doi: 10.1016/j.commatsci.2013.01.018.

Li, J. C. M., Oriani, R. A., and Darken, L. S. (1966). The thermodynamics of stressed solids. Zeitschrift für Physikalische Chemie, 49, 271-290. doi: 10.1524/zpch.1966.49.3_5.271.

Li, J.-X., Oudriss, A., Metsue, A., Bouhattate, J., and Feaugas, X. (2017). Anisotropy of hydrogen diffusion in nickel single crystals: the effects of self-stress and hydrogen concentration on diffusion. Scientific Reports, 7, 45041. doi: $10.1038 /$ srep45041.

Lord, A. E. and Beshers, D. N. (1965). Elastic stiffness coefficients of iron from $77^{\circ}$ to $673^{\circ} \mathrm{K}$. Journal of Applied Physics, 36, 1620-1625. doi: 10.1063/1.1703098.

Lu, G., Orlikowski, D., Park, I., Politano, O., and Kaxiras, E. (2002). Energetics of hydrogen impurities in aluminum and their effect on mechanical properties. Physical Review B, 65, 064102. doi: 10.1103/PhysRevB.65.064102.

Lynch, S. (2019). Discussion of some recent literature on hydrogen-embrittlement mechanisms: addressing common misunderstandings. Corrosion Reviews, 136. doi: 10.1515/corrrev-2019-0017.

Martin, M. L., Dadfarnia, M., Nagao, A., Wang, S., and Sofronis, P. (2019). Enumeration of the hydrogen-enhanced localized plasticity mechanism for hydrogen embrittlement in structural materials. Acta Materialia, 165, 734-750. doi: 10.1016/j.actamat.2018.12.014.

Martínez-Pañeda, E., Niordson, C. F., and Gangloff, R. P. (2016). Strain gradient plasticity-based modeling of hydrogen environment assisted cracking. Acta Materialia, 117, 321-332. doi: 10.1016/j.actamat.2016.07.022.

McNabb, A. and Foster, P. K. (1963). A new analysis of the diffusion of hydrogen in iron and ferritic steels. Transactions of the Metallurgical Society of AIME, 227, $618-627$. 
Melitz, W., Shen, J., Kummel, A. C., and Lee, S. (2011). Kelvin probe force microscopy and its application. Surface Science Reports, 66, 1-27. doi: 10.1016/j.surfrep.2010.10.001.

Metsue, A., Oudriss, A., and Feaugas, X. (2018). Trapping/detrapping kinetic rates of hydrogen around a vacancy in nickel and some consequences on the hydrogenvacancy clusters thermodynamic equilibrium. Computational Materials Science, 151, 144-152. doi: 10.1016/j.commatsci.2018.05.013.

Miresmaeili, R., Ogino, M., Nakagawa, T., and Kanayama, H. (2010). A coupled elastoplastic-transient hydrogen diffusion analysis to simulate the onset of necking in tension by using the finite element method. International Journal of Hydrogen Energy, 35, 1506-1514. doi: 10.1016/j.ijhydene.2009.11.024.

Moriconi, C., Hénaff, G., and Halm, D. (2014). Cohesive zone modeling of fatigue crack propagation assisted by gaseous hydrogen in metals. International Journal of Fatigue, 68, 56-66. doi: 10.1016/j.ijfatigue.2014.06.007.

Müller, C., Zamanzade, M., and Motz, C. (2019). The impact of hydrogen on mechanical properties; a new in situ nanoindentation testing method. Micromachines, 10, 114. doi: 10.3390/mi10020114.

Oda, T., Zhu, D., and Watanabe, Y. (2015). Kinetic Monte Carlo simulation on influence of vacancy on hydrogen diffusivity in tungsten. Journal of Nuclear Materials, 467, 439-447. doi: 10.1016/j.jnucmat.2015.07.054.

Oh, C.-S., Kim, Y. J., and Yoon, K. B. (2010). Coupled analysis of hydrogen transport using ABAQUS. Journal of Solid Mechanics and Materials Engineering, 4, 908-917. doi: 10.1299/jmmp.4.908.

Olden, V., Saai, A., Jemblie, L., and Johnsen, R. (2014). FE simulation of hydrogen diffusion in duplex stainless steel. International Journal of Hydrogen Energy, 39, 1156-1163. doi: http://dx.doi.org/10.1016/j.ijhydene.2013.10.101.

Olden, V., Thaulow, C., Johnsen, R., Østby, E., and Berstad, T. (2009). Influence of hydrogen from cathodic protection on the fracture susceptibility of $25 \% \mathrm{Cr}$ duplex stainless steel - constant load SENT testing and FE-modelling using hydrogen influenced cohesive zone elements. Engineering Fracture Mechanics, 76, 827-844. doi: 10.1016/j.engfracmech.2008.11.011.

Oriani, R. A. (1970). The diffusion and trapping of hydrogen in steel. Acta Metallurgica, 18, 147-157. doi: 10.1016/0001-6160(70)90078-7.

Osman Hoch, B., Metsue, A., Bouhattate, J., and Feaugas, X. (2015). Effects of grain-boundary networks on the macroscopic diffusivity of hydrogen in polycrystalline materials. Computational Materials Science, 97, 276-284. doi: 10.1016/j.commatsci.2014.10.048.

Oudriss, A., Creus, J., Bouhattate, J., Savall, C., Peraudeau, B., and Feaugas, X. (2012). The diffusion and trapping of hydrogen along the grain boundaries in polycrystalline nickel. Scripta Materialia, 66, 37-40. doi: 10.1016/j.scriptamat. 2011.09.036. 
Peirce, D., Asaro, R. J., and Needleman, A. (1982). An analysis of nonuniform and localized deformation in ductile single crystals. Acta Metallurgica, 30, 1087-1119. doi: 10.1016/0001-6160(82)90005-0.

Pfretzschner, B., Schaupp, T., and Griesche, A. (2019). Hydrogen in metals visualized by neutron imaging. Corrosion, 75, 903-910. doi: 10.5006/3104.

Pouillier, E., Gourgues, A. F., Tanguy, D., and Busso, E. P. (2012). A study of intergranular fracture in an aluminium alloy due to hydrogen embrittlement. International Journal of Plasticity, 34, 139-153. doi: 10.1016/j.ijplas.2012.01.004.

Quey, R., Dawson, P. R., and Barbe, F. (2011). Large-scale 3D random polycrystals for the finite element method: generation, meshing and remeshing. Computer Methods in Applied Mechanics and Engineering, 200, 1729-1745. doi: 10.1016/ j.cma.2011.01.002.

Ramasubramaniam, A., Itakura, M., Ortiz, M., and Carter, E. A. (2008). Effect of atomic scale plasticity on hydrogen diffusion in iron: quantum mechanically informed and on-the-fly kinetic Monte Carlo simulations. Journal of Materials Research, 23, 2757-2773. doi: 10.1557/JMR.2008.0340.

Rimoli, J. J. and Ortiz, M. (2010). A three-dimensional multiscale model of intergranular hydrogen-assisted cracking. Philosophical Magazine, 90, 2939-2963. doi: $10.1080 / 14786431003752134$.

Salahouelhadj, A. and Haddadi, H. (2010). Estimation of the size of the RVE for isotropic copper polycrystals by using elastic-plastic finite element homogenisation. Computational Materials Science, 48, 447-455. doi: 10.1016/j.commatsci. 2009.12.014.

Sezgin, J.-G., Takatori, D., and Yamabe, J. (2019). Anisotropy of cold-worked Type-304 austenitic stainless steel: focus on the hydrogen diffusivity. International Journal of Hydrogen Energy, 44, 20516-20528. doi: 10.1016/j.ijhydene. 2019.05.175.

Shibamoto, Y., Mikami, Y., and Mochizuki, M. (2017). Modeling of hydrogen diffusion behavior considering the microstructure of duplex stainless steel weld metal. Quarterly Journal of the Japan Welding Society, 35, 23-27.

Sills, R. B. and Cai, W. (2016). Solute drag on perfect and extended dislocations. Philosophical Magazine, 96, 895-921. doi: 10.1080/14786435.2016.1142677.

Simulia. (2011). Abaqus User Subroutines Reference Guide. Dassault Système.

Sofronis, P. and McMeeking, R. M. (1989). Numerical analysis of hydrogen transport near a blunting crack tip. Journal of the Mechanics and Physics of Solids, 37, 317-350. doi: 10.1016/0022-5096(89)90002-1.

Song, J. and Curtin, W. A. (2011). A nanoscale mechanism of hydrogen embrittlement in metals. Acta Materialia, 59, 1557-1569. doi: 10.1016/ j.actamat.2010.11.019. 
Swiler, T. P., Tikare, V., and Holm, E. A. (1997). Heterogeneous diffusion effects in polycrystalline microstructures. Materials Science and Engineering: A, 238, 85-93. doi: 10.1016/S0921-5093(97)00441-3.

Taha, A. and Sofronis, P. (2001). A micromechanics approach to the study of hydrogen transport and embrittlement. Engineering Fracture Mechanics, 68, 803-837. doi: http://dx.doi.org/10.1016/S0013-7944(00)00126-0.

Takayama, K., Matsumoto, R., Taketomi, S., and Miyazaki, N. (2011). Hydrogen diffusion analyses of a cracked steel pipe under internal pressure. International Journal of Hydrogen Energy, 36, 1037-1045. doi: 10.1016/j.ijhydene.2010.10.046.

Taketomi, S., Imanishi, H., and Matsumoto, R. (2013). Dislocation dynamics analysis of hydrogen embrittlement in alpha iron based on atomistic investigations. Presented at the 13th International Conference on Fracture, Beijing, China.

Tehranchi, A. and Curtin, W. A. (2019). The role of atomistic simulations in probing hydrogen effects on plasticity and embrittlement in metals. Engineering Fracture Mechanics, 216, 106502. doi: 10.1016/j.engfracmech.2019.106502.

Traidia, A., Chatzidouros, E., and Jouiad, M. (2018). Review of hydrogen-assisted cracking models for application to service lifetime prediction and challenges in the oil and gas industry. Corrosion Reviews, 36, 323-347. doi: 10.1515/corrrev-20170079 .

Turk, A., Bombač, D., Jelita Rydel, J., Ziętara, M., Rivera-Díaz-del-Castillo, P. E. J., and Galindo-Nava, E. I. (2018). Grain boundary carbides as hydrogen diffusion barrier in a Fe-Ni alloy: a thermal desorption and modelling study. Materials \& Design, 160, 985-998. doi: 10.1016/j.matdes.2018.10.012.

Van der Ven, A. and Ceder, G. (2003). Impurity-induced van der Waals transition during decohesion. Physical Review B, 67, 060101. doi: 10.1103/PhysRevB. 67.060101 .

Vasikaran, E., Charles, Y., and Gilormini, P. (2019). Implantation of a reactiondiffusion Process in Abaqus software. Mech Indus, submitted.

Vasios, N. (2015). Crystal Plasticity. University of Thessaly, Greece.

Verners, O., Psofogiannakis, G., and van Duin, A. C. T. (2015). Comparative molecular dynamics study of fcc-Al hydrogen embrittlement. Corrosion Science, 98, 40-49. doi: 10.1016/j.corsci.2015.05.008.

Wen, M., Xu, X.-J., Omura, Y., Fukuyama, S., and Yokogawa, K. (2004). Modeling of hydrogen embrittlement in single crystal Ni. Computational Materials Science, 30, 202-211. doi: 10.1016/j.commatsci.2004.02.047.

Wu, Q. and Zikry, M. A. (2015). Prediction of diffusion assisted hydrogen embrittlement failure in high strength martensitic steels. Journal of the Mechanics and Physics of Solids, 85, 143-159. doi: 10.1016/j.jmps.2015.08.010. 
Xu, T. H., Zhu, Z. Q., Geng, S. F., and Song, H. Y. (2017). Molecular dynamics study of effect of hydrogen atoms on mechanical properties of $\alpha$-Fe nanowires. Physics Letters A, 381, 3222-3227. doi: 10.1016/j.physleta.2017.08.012.

Yan, C., Liu, C., and Yan, B. (2014). 3D modeling of the hydrogen distribution in X80 pipeline steel welded joints. Computational Materials Science, 83, 158-163. doi: 10.1016/j.commatsci.2013.11.007.

Yazdipour, N., Haq, A. J., Muzaka, K., and Pereloma, E. V. (2012). 2D modelling of the effect of grain size on hydrogen diffusion in X70 steel. Computational Materials Science, 56, 49-57. doi: 10.1016/j.commatsci.2012.01.003.

Yu, H., Cocks, A., and Tarleton, E. (2019). Discrete dislocation plasticity HELPs understand hydrogen effects in bec materials. Journal of the Mechanics and Physics of Solids, 123, 41-60. doi: 10.1016/j.jmps.2018.08.020.

Yu, H., Olsen, J. S., Olden, V., Alvaro, A., He, J., and Zhang, Z. (2017). Cohesive zone simulation of grain size and misorientation effects on hydrogen embrittlement in nickel. Engineering Failure Analysis, 81, 1-35. doi: 10.1016/j.engfailanal. 2017.07.027.

Zhang, Y., Jiang, C., and Bai, X. (2017). Anisotropic hydrogen diffusion in $\alpha-Z r$ and Zircaloy predicted by accelerated kinetic Monte Carlo simulations. Scientific Reports, 7, 41033. doi: 10.1038/srep41033.

Zhu, J., Chen, L. Q., Shen, J., and Tikare, V. (2001). Microstructure dependence of diffusional transport. Computational Materials Science, 20, 37-47. doi: 10.1016/S0927-0256(00)00123-3. 